\title{
Loss of miR-673-5p expression in the cornea promotes rat corneal allograft rejection by promoting Th17 cell differentiation mediated by JAK2/STAT3
}

\author{
Qian Cao, Yunchuan Li, Yong Li, Lan Li \\ Department of Ophthalmology, the Affiliated Calmette Hospital of Kunming Medical University, Kunming, China \\ Contributions: (I) Conception and design: L Li; (II) Administrative support: L Li; (III) Provision of study materials or patients: Q Cao; (IV) Collection \\ and assembly of data: Q Cao, YC Li; (V) Data analysis and interpretation: Q Cao, Y Li; (VI) Manuscript writing: All authors; (VII) Final approval of \\ manuscript: All authors. \\ Correspondence to: Lan Li. Department of Ophthalmology, the Affiliated Calmette Hospital of Kunming Medical University, No. 1228 Beijing Road, \\ Panlong District, Kunming 650000, China. Email: lanli2021@163.com.
}

\begin{abstract}
Background: Cluster of differentiation 4 positive $\left(\mathrm{CD}_{4}^{+}\right) \mathrm{T}$ cells play an important role in corneal graft rejection, especially the dynamic balance between regulatory $\mathrm{T}$ cells and helper $\mathrm{T}$ cells. This study aims to explore the upstream and downstream regulatory mechanisms of Th17 cell differentiation-mediated corneal allograft rejection.

Methods: By establishing rat corneal allograft transplantation model, transcriptome analysis was carried out to screen the differentially expressed genes related to T helper 17 (Th17) cell differentiation, and then cell experiments were used to verify the effect of miR-673-5p/Janus Kinase 2 (JAK2) signal on naive $\mathrm{CD}_{4}{ }^{+}$ $\mathrm{T}$ cell differentiation and the proliferation, migration, and tube formation ability of human umbilical vein endothelial cells (HUVECs). Finally, the role of miR-673-5p/JAK2 signal in corneal allograft rejection was verified by animal model in vivo.

Results: The results showed that JAK2/STAT3 signaling activation-mediated Th17 cell differentiation was significantly up-regulated during corneal allograft rejection, and miR-673-5p expression was down-regulated after corneal allograft rejection. Low expression of miR-673-5p promoted Th17 cell differentiation by up-regulating JAK2, and then promoted placental growth factor (PLGF)mediated corneal neovascularization (CNV).

Conclusions: The results of this study suggested that low expression of miR-673-5p is a promoter of corneal allograft rejection. Overexpression of miR-673-5p can improve the survival rate of corneal allografts by inhibiting the differentiation and maturation of Th17 cells mediated by JAK2/STAT3 signaling.
\end{abstract}

Keywords: Corneal allograft rejection; Th17 cell differentiation; corneal neovascularization (CNV); miR-673-5p; JAK2

Submitted Feb 24, 2021. Accepted for publication Aug 26, 2021.

doi: $10.21037 / \mathrm{atm}-21-2051$

View this article at: https://dx.doi.org/10.21037/atm-21-2051

\section{Introduction}

A variety of corneal diseases, such as keratitis, corneal degeneration, corneal chemical injury, may lead to corneal blindness, and decrease of personal labor force, thus leading to substantial mental trauma for patients as well as considerable family and social problems. At present, corneal transplantation is the only way to restore vision in patients with corneal blindness (1). However, graft rejection following transplantation results in many endothelial cells, which maintains corneal transparency. Even under conditions of local and systemic immunosuppressive treatment, the failure rate of corneal transplantation may still exceed 50\% (2), resulting in poor vision correction and even blindness again. 
Cellular immunity plays an important role in allograft rejection. As an immune cell, Cluster of differentiation 4 positive $\left(\mathrm{CD}_{4}^{+}\right) \mathrm{T}$ cells can independently mediate corneal allograft rejection $(3,4)$, and the down-regulation of $\mathrm{CD}_{4}{ }^{+} \mathrm{T}$ cell immunity is related to the improvement of corneal graft survival (5). As a subtype of activated $\mathrm{CD}_{4}{ }^{+}$ $\mathrm{T}$ cells, T helper 17 (Th17) cells specifically express the transcription factor retinoic acid-receptor (RAR)-related orphan receptor- $\gamma \mathrm{t}(\mathrm{ROR} \gamma \mathrm{t})$, and are reported to mediate corneal allograft rejection by secreting pro-inflammatory cytokine interleukin 17 (IL-17) (6-8). According to previous studies, Janus Kinase 2/ Signal Transducer and Activator of Transcription 3 (JAK2/STAT3) signaling and the activity of STAT3 play important roles in Th17 differentiation (9-11). An experimental study has shown that IL-1 $\beta$ mediated by NOD-like receptor family pyrin domain containing 3 (NLRP3) inflammasome promotes Th17 differentiation through STAT3 phosphorylation, thus aggravating mice corneal allograft rejection (12). In addition, numerous studies have shown that microRNAs (miRNAs) are widely involved in the regulation of Th17 cell differentiation (13-16). Previous studies have also revealed that miRNAs participate in the progress of corneal allograft rejection $(17,18)$. However, reports of a direct relationship between miRNA and corneal transplantation rejection are limited.

Corneal neovascularization (CNV) is considered to be an important risk factor for allograft rejection following corneal transplantation $(19,20)$. The avascular nature of cornea is attributed to the balance between angiogenic factors and antiangiogenic factors. However, under pathological conditions, this homeostasis may be disturbed and lead to CNV $(21,22)$. Placental growth factor (PLGF) is a member of vascular endothelial growth factor (VEGF) family, and its expression is related to pathological angiogenesis and inflammation (23). Studies have shown that PLGF promotes the development of CNV, and its derivative peptide ZY-1 can inhibit PLGF-induced CNV $(24,25)$. In addition, a previous study has shown that PLGF can be selectively secreted by Th17 cells and promote angiogenesis, and can also activate STAT3 to promote Th17 cell differentiation, which can interfere with the vascular endothelial cells of helper T cells (26). Therefore, PLGF is a kind of "angio-lymphokine" that links autoimmunity with angiogenesis. Although, whether Th17 cells promote neovascularization by secreting PLGF following corneal transplantation needs to be further investigated.

The present study aims to explore the role of miRNAs in Th17 cell activation mediated corneal allograft rejection, and to elucidate the molecular mechanism of promoting Th17 cell differentiation and PLGF-mediated CNV via JAK2/STAT3 signaling. By establishing a rat model of allogenic penetrating keratoplasty and transcriptome sequencing, miR-673-5p was confirmed to regulate Th17 cell differentiation by targeting JAK2, thus regulating the proliferation, migration, and angiogenesis of vascular endothelial cells mediated by PLGF, which was secreted by Th17 cells. Low expression of mir-673-5p was found to promote the development of corneal allograft rejection, while overexpression of miR-673-5p could inhibit Th17 differentiation and CNV-mediated corneal allograft rejection, and improve graft survival rate. We present the following article in accordance with the ARRIVE reporting checklist (available at https://dx.doi.org/10.21037/atm-212051).

\section{Methods}

Establishment of an allogenic penetrating keratoplasty rat model and transcriptome sequencing analysis

Adult female Sprague-Dawley rats, weighing 220-250 g without eye disease were obtained from Hunan SJA Laboratory Animal Co., Ltd. (Certificate number 43004700043639, China). All rats were housed individually with a $12 \mathrm{~h} \mathrm{light/dark} \mathrm{cycle} \mathrm{at} 22{ }^{\circ} \mathrm{C}$ with $50 \%$ humidity and received ad libitum access to food and water. All animal experimental protocols were approved by the Animal Experimental Ethical Inspection of the Affiliated Calmette Hospital of Kunming Medical University (Approval No. YLS2020-18), and the animals were handled according to the management requirements of the Animal Management Association of the Affiliated Calmette Hospital of Kunming Medical University. A protocol was prepared before the study without registration. The right eye was taken as the operation eye, and the left normal eye was reserved, which did not affect the postoperative food intake of rats.

The rat model of allogenic penetrating keratoplasty with donation after cardiac death (DCD) was established as previously described (27). The eyelid sutures were cut $24 \mathrm{~h}$ postoperatively, and were then observed and photographed under a stereomicroscope (Olympus, Tokyo, Japan). Successful modeling criteria: no graft wound dehiscence, anterior chamber infection, intraocular infection, or other complications occurred within 3 days postoperatively. Observation was made once a day within 1 week after 
Table 1 Criteria of rejection after corneal transplantation

\begin{tabular}{|c|c|c|c|}
\hline Score & Graft opacity & Graft edema & Graft neovascularization \\
\hline 1 & Slightly turbid & $\begin{array}{l}\text { Corneal stroma was slightly edematous } \\
\text { and thickened }\end{array}$ & CNV around implantation bed \\
\hline 2 & $\begin{array}{l}\text { Opacity increased, but the iris texture was } \\
\text { still visible }\end{array}$ & Diffuse corneal stromal edema & $\begin{array}{l}\text { Neovascularization reaches the peripheral } \\
\text { part of the graft }\end{array}$ \\
\hline 4 & $\begin{array}{l}\text { Completely cloudy, the anterior chamber } \\
\text { cannot be seen }\end{array}$ & Bullous keratopathy & $\begin{array}{l}\text { Neovascularization covered the corneal } \\
\text { graft }\end{array}$ \\
\hline
\end{tabular}

CNV, corneal neovascularization.

surgery, and every other day after this initial 1-week period. The opacity, edema, and neovascularization indexes of the corneal graft were recorded and scored according to Larkin DF standard (Table 1). The sum of the three scores was the rejection index (RI), and corneal rejection was defined when $\mathrm{RI} \geq 6$, according to previous research (28).

For transcriptome sequencing (RNA-Seq) analysis, rats were executed with anesthesia at 21 days postoperatively $(\mathrm{RI} \geq 6)$. Rejected corneal allografts $(\mathrm{n}=36)$ were then collected and total RNA was extracted for RNA-Seq analysis. Donor corneal grafts $(\mathrm{n}=36)$ were used as a control to determine the relative expression level of RNA in the corneal graft of the rejection group. RNA-Seq analysis was performed by Hangzhou Lianchuan Biotechnology Co., Ltd. (Hangzhou, China).

To further study the effect and mechanism of miR673-5p in vivo, $5 \mathrm{nmol}$ of miR-673-5p mimics or JAK2 overexpression lentiviral vector (oe-JAK2, Guangzhou RiboBio Biotechnology Co., Ltd., Guangzhou, China) in sterile phosphate buffer (PBS) were applied as topical eye drops to the rats $24 \mathrm{~h}$ after corneal transplantation surgery for the first time, and then 4 times daily until the RI of rat in rejection control group (used sterile PBS as eye drops) all reached 6 . The treatment of rat was performed according to previous study (17).

\section{Histopathological evaluation and immunohistochemical staining}

Corneal grafts were collected from each group 21 days after surgery, fixed in $4 \%$ paraformaldehyde, embedded in paraffin, and sliced into $5 \mu \mathrm{m}$-thick sections. Subsequently, the sections were stained using a hematoxylin and eosin
(H\&E) staining kit (Solaria, China) to observe the corneal histomorphology changes and inflammatory cell infiltration. Immunohistochemical staining of corneal grafts was performed to observe the expression of VEGF and PLGF in corneal grafts using the primary antibodies against VEGF (1:100, Abcam, UK) or PLGF (1:100, Abcam, UK). The histological changes of the brain were observed under a microscope (OLYMPUS, Japan).

\section{Cell culture and treatment}

Naïve $\mathrm{CD}_{4}{ }^{+} \mathrm{T}$ cells from the spleens of 6-8-week-old Sprague-Dawley rats were isolated and purified using the magnetic microbead $\mathrm{T}$ cell isolation method, according to a previous study (29), and were then cultured in complete Roswell Park Memorial Institute 1640 (RPMI-1640) medium. To polarize the Th17 cells, the naïve $\mathrm{CD}_{4}{ }^{+} \mathrm{T}$ cells were treated by exogenous cytokines and antibodies, according to a previous report (12).

To investigate the influence of miR-673-5p expression on Th17 cell differentiation, miR-673-5p mimics and miR-673-5p inhibitor were purchased from Guangzhou RiboBio Biotechnology Co., Ltd. (Guangzhou, China), and transfected into naïve $\mathrm{CD}_{4}^{+} \mathrm{T}$ cells with Lipofectamine ${ }^{\circledR}$ 2000 transfection reagent (Invitrogen, Thermo Fisher Scientific, Inc., USA) according to the manufacturer's instructions. Additionally, to further study whether miR673-5p regulates Th17 cell differentiation via JAK2/STAT3 signaling, the inhibitor of JAK2/STAT3, AG490 (10 $\mu \mathrm{M}$, MCE, China) was used to treat naïve $\mathrm{CD}_{4}^{+} \mathrm{T}$ cells to inhibit the activation of JAK2/STAT3 signaling.

To determine whether low expression of miR-673-5pinduced Th17 cell differentiation promoted angiogenesis, 
human umbilical vein endothelial cells (HUVECs) purchased from BeNa Culture Collection (BNCC, China) were cultured in a 24-well plate with complete Dulbecco's Modified Eagle Medium (DMEM) medium containing $10 \%$ fetal bovine serum (FBS) and 1\% (v/v) penicillin/ streptomycin. Next, the HUVECs were treated with the culture medium (CM) from each group of $\mathrm{CD}_{4}{ }^{+} \mathrm{T}$ cells (200 $\mu \mathrm{L}$ of supernatant after centrifugation at $3,000 \times g$ for $3 \mathrm{~min}$ ). In addition, PLGF-1 derived peptide, ZY-1 ("CVSLLRCTGCCAAAN AHCVPV", commercially synthesized by Wuhan Bioyeargene Biotechnology Co., Ltd., Wuhan, China) was used to inhibit PLGF-1 binding to vascular endothelial growth factor receptor 1 (VEGFR-1) at a dosage of $2.5 \mathrm{mM}$.

\section{Flow cytometry}

Peripheral blood and aqueous humor were collected from three rats per group $21 \mathrm{~d}$ after corneal transplantation surgery, and mononuclear cells were separated using Ficoll-Paque gradient centrifugation according to the manufacturer's instructions (Tianjin Haoyang Biological Manufacture Co., Ltd., Tianjin, China). The percentage of Th17 cells in peripheral blood, aqueous humor, and cultured $\mathrm{CD}^{+} \mathrm{T}$ cells was detected by flow cytometry using antibodies against CD4, CD25, and ROR $\gamma$ t (Abcam, UK), which was performed using the FACS Verse flow cytometer (Becton Dickinson Biosciences, Franklin Lakes, NJ, USA) and analyzed using FlowJo v10 (FlowJo, Ashland, USA).

\section{ELISA assay}

Concentrations of IL-17 and PLGF in rat peripheral blood and aqueous humor $21 \mathrm{~d}$ after corneal transplantation surgery, and in the $\mathrm{CM}$ of $\mathrm{CD}^{+} \mathrm{T}$ cells, were measured by enzyme-linked immunosorbent assay (ELISA) using a rat IL-17 and rat PLGF ELISA Kit (Shanghai Enzyme-linked Biotechnology Co., Ltd., Shanghai, China).

\section{Dual luciferase reporter assay}

The binding sites between miR-673-5p and JAK2 were predicted with TargetScan v7.2, (ULR: http://www. targetscan.org/vert_72/). Luciferase vectors containing the 3' untranslated regions ( 3 'UTR) of rat JAK2 with the miR673-5p binding sites and mutant miR-673-5p binding sites were purchased from Shanghai GenePharma Co., Ltd.
Subsequently, the vectors were co-transfected with miR$673-5$ p mimics into 293 T cells using the Lipofectamine ${ }^{\circledR}$ 2000 transfection reagent (Invitrogen; Thermo Fisher Scientific, Inc.; USA). After 48 h, the luciferase reporter activity was determined using a Dual-Luciferase ${ }^{\circledR}$ Reporter Assay System (Promega Corporation, USA).

\section{Real-time fluorescent quantitative PCR (RT-qPCR)}

The total RNA of corneal grafts was extracted with TRIzol reagent (Invitrogen; Thermo Fisher Scientific, Inc.; USA). Next, the expression of miRNA and mRNA was measured by RT-qPCR performed on triplicate samples with ABI 7500 Real-Time PCR System (Applied Biosystems; Thermo Fisher Scientific, Inc.; USA). The relative expressions of mRNA and miRNA were presented as fold changes with the $2^{-\triangle \Delta C T}$ method, and GAPDH and U6 were used to normalize the mRNA and miRNA levels, respectively. The primer sequences used were as follows: rat GAPDH, forward: 5'-CCTCGTCTCATAGACAAGATGGT-3' and reverse: 5'-GGGTAGAGTCATACTGGAACATG-3'; rat U6, forward: 5'-GGTCCAGTTTTTTTTTTTTTTTCCA-3' and reverse: 5'-AACGCTTCACGAATTTGCGT-3'; rat JAK2, forward: 5'-CACCAACATTACAGAGGCATAATA-3' and reverse: 5'-GAACGACGAAGCTTCTTTCTGAG-3'; rat miR-673-5p, forward: 5'-CACAGCTCCGGTCCT-3' and reverse: 5'-GGTCCAGTTTTTTTTTTTTTTTCCA-3'.

\section{Western blotting}

The protein expression levels in corneal grafts $21 \mathrm{~d}$ after corneal transplantation surgery and cultured $\mathrm{CD}^{+} \mathrm{T}$ cells were measured by western blot assays using the primary antibodies against IL-17, JAK2, p-JAK2, STAT3, p-STAT3, vascular endothelial growth factor A (VEGFA), and PLGF at a dilution of 1:1,000 (Abcam, UK). Anti-GAPDH was used as the loading control, and the grayscale value analysis was performed using Image J software (version $1.52 \mathrm{a}$; National Institutes of Health).

\section{Cell proliferation and migration}

The proliferation of HUVECs with or without treatment by $\mathrm{CM}$ of $\mathrm{CD}^{+} \mathrm{T}$ cells was determined by Ki67 staining using Ki67 antibody, according to a previous report (30). The migration of HUVECs was determined by the cell scratch test and transwell assay, according to previous studies $(30,31)$. 


\section{Tube forming assay}

$1 \times 10^{5}$ HUVECs with or without treatment by $\mathrm{CM}$ of $\mathrm{CD} 4^{+}$ $\mathrm{T}$ cells were plated into a 24 -well plate coated with the growth factor-reduced Matrigel (BD Biosciences, China). After $24 \mathrm{~h}$ of culturing, the tube formation was observed using a bright-field microscope (Olympus, Tokyo, Japan). The tube length was quantified using Image $J$ software (version 1.52a; National Institutes of Health).

\section{Statistical analysis}

All cell experiments were repeated three times and the data were presented as the mean \pm standard error of mean (SEM). Differences between two or multiple groups were evaluated using a two-tailed Student's $t$-test, one-way analysis of variance (ANOVA), or two-way ANOVA followed by Bonferroni post hoc test. The difference in survival rates among the various groups was compared using log-rank (Mantel-Cox) test. Statistical analyses were performed using GraphPad Prism 7.0 software (GraphPad Software, Inc., CA, USA). $\mathrm{P}<0.05$ was considered to indicate a statistically significant difference.

\section{Results}

\section{Rejection of corneal allograft}

Increasing evidence has shown that $\mathrm{T}$ cell responses and Th17 cells are involved in corneal allograft survival $(12,32)$. However, whether the proportion of Th17 cells changes after corneal transplantation, as well as its regulatory mechanism, still need to be further studied. After corneal transplantation, the opacity, edema, and neovascularization of the corneal grafts were examined using stereomicroscope and scored for 3 weeks. As a result, the rejection rate of corneal allograft in the operative group at $21 \mathrm{~d}$ postoperatively was almost $100 \%$, which showed obvious opacity, edema, and neovascularization compared with normal cornea (control group, as shown in Figure 1A).

$\mathrm{H} \& \mathrm{E}$ staining showed that there were a number of inflammatory cells, obvious edema, and neovascularization observed in the stroma of rejected corneal grafts (Figure 1B). Immunohistochemical staining of corneal grafts showed that VEGF was expressed to significantly higher level in rejected corneal grafts (Figure 1C). In addition, the expressions of JAK2 and IL-17 in corneal grafts were up-regulated after rejection (Figure 1D-1F). Flow cytometry showed that the ratio of Th17 cells in aqueous humor and peripheral blood of rats was significantly increased after graft rejection, especially in the aqueous humor (Figure 1G). Meanwhile, the concentration of IL-17 and PLGF in the aqueous humor and peripheral blood was also obviously increased after graft rejection (Figure 1H). These results indicate that the upregulation of JAK2 and PLGF may be involved in Th17 cell differentiation and neovascularization-induced corneal allograft rejection, however the molecular mechanism involved in this progression remains unclear.

\section{Changes in the RNA expression profile}

To investigate whether the miRNA and mRNA expression profile change when corneal allografts rejection occur, miRNA-Seq and mRNA-Seq were performed. As the results demonstrate, there was a larger number of mRNAs up- or down-regulated in rejected corneal grafts compared with normal corneas (Figure 2A). Gene Ontology (GO) enrichment statistics showed that part of mRNAs was enriched in the inflammatory response, cell migration, and angiogenesis, while Kyoto Encyclopedia of Genes and Genomes (KEGG) pathway enrichment showed part of mRNAs are enriched in allograft rejection, Th1 and Th2 cell differentiation, and Th17 cell differentiation (Figure 2B,2C). Simultaneously, there was also numbers of miRNAs differentially expressed in control group and rejected corneal graft (Figure 2D), and some miRNAs are enriched in protein binding, cytoplasm, and transferase activity by GO enrichment, while some miRNAs are also enriched in Th17 cell differentiation, Th1 and Th2 cell differentiation, and allograft rejection (Figure 2E,2F).

In order to further study the molecular regulation mechanism of Th17 cell differentiation, mRNAs and miRNAs enriched on Th17 cell differentiation were further analyzed (Figure 2G,2H), and the expression of JAK2 mRNA in the corneal allografts of the rejection group was obviously increased (Figure 2G), it is worth noting that JAK2 is also enriched in the Th17 cell differentiation pathway and JAK/ STAT pathway by KEGG (seen available online https:// cdn.amegroups.cn/static/public/atm-21-2051-01.zip). The interaction analysis of mRNA and miRNA enriched in the Th17 cell differentiation pathway showed that miR673-5p, which exhibited low expression in rejected corneal allografts (Figure 2H), could target JAK2 mRNA (Figure 2I). Further RT-qPCR experiments showed JAK2 mRNA and miR-673-5p were identically differentially expressed in rejected corneal allografts compared with normal corneas (Figure 27,2K). These results suggest that low expression of miR-673-5p may be a promoter of allograft rejection, 
A
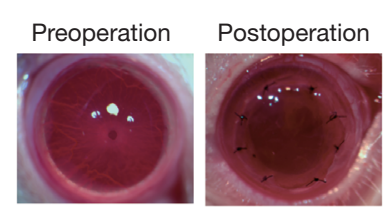

C
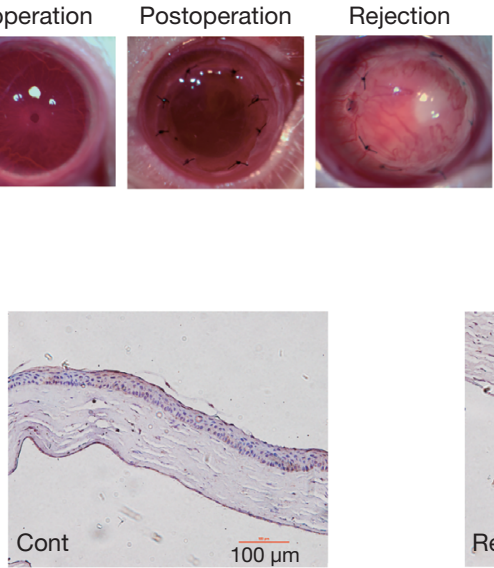

B
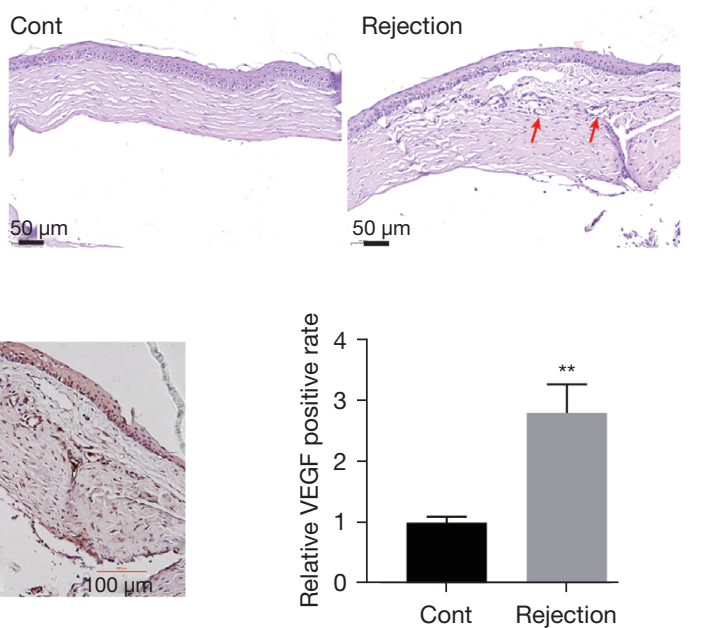

$\mathrm{F}$
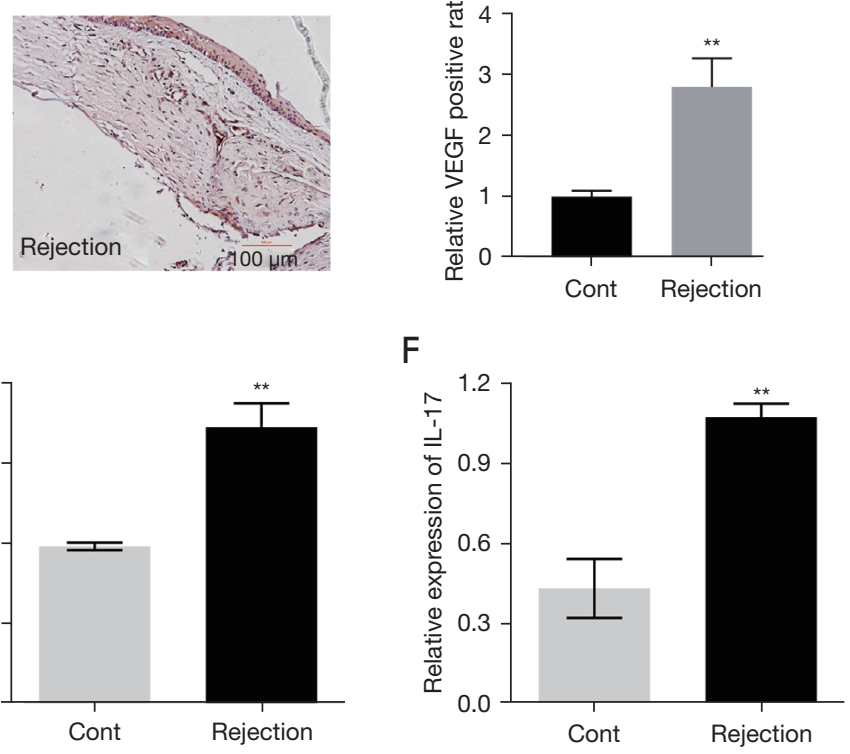

D
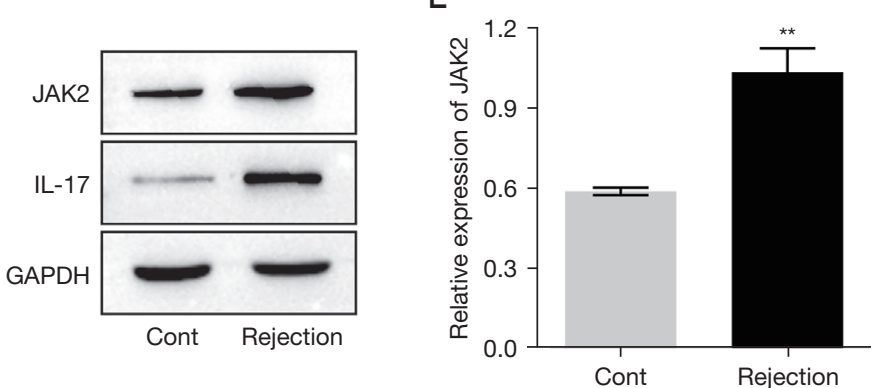

$\mathrm{E}$

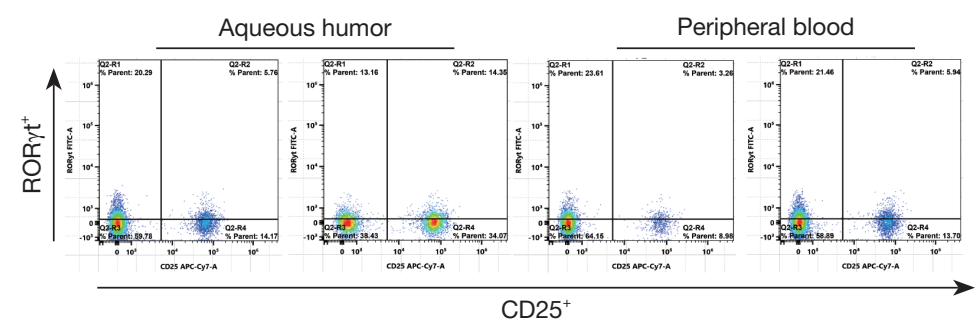

G

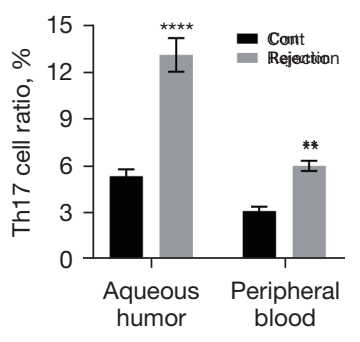

$\mathrm{H}$

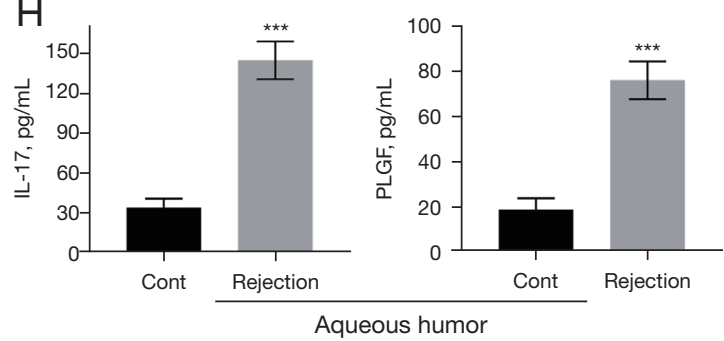

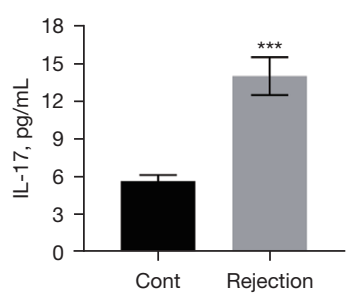

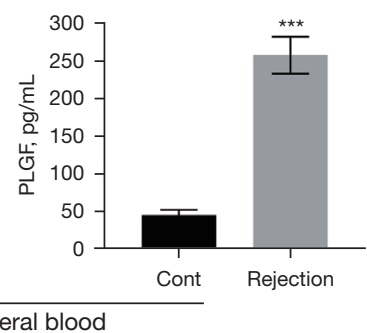

Figure 1 Th17 cell differentiation and CNV in corneal allograft rejected rats. (A) Representative images of corneal allografts $21 \mathrm{~d}$ after transplantation and normal corneas; (B) representative images of H\&E staining on corneal allografts; the red arrows showed the neovascularization in corneal allografts; (C) immunohistochemical staining of corneal allografts by anti-VEGF antibody; (D-F) relative expressions of JAK2 and IL-17 in corneal allografts; (G) the ratio of Th17 cells in aqueous humor and peripheral blood of rats at $21 \mathrm{~d}$ after corneal transplantation; (H) concentrations of IL-17 and PLGF in aqueous humor and peripheral blood. ${ }^{* *} \mathrm{P}<0.01,{ }^{* * *} \mathrm{P}<0.001,{ }^{* * * *} \mathrm{P}<0.0001$ vs. control group. Cont, control group; Rejection, corneal allograft rejected group; CNV, corneal neovascularization; VEGF, vascular endothelial growth factor; PLGF, placental growth factor. 
A

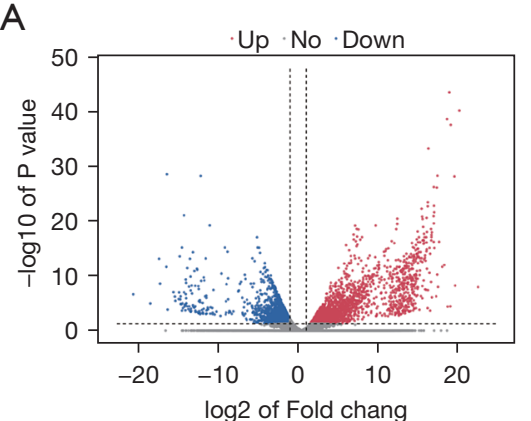

D

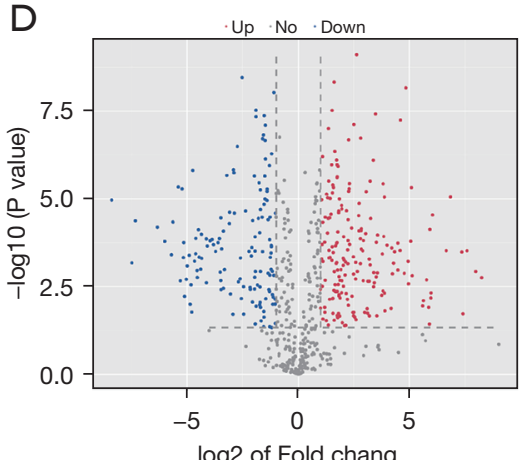

G

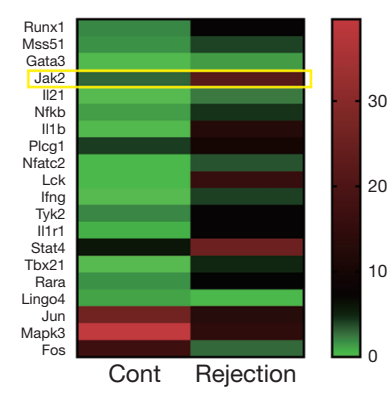

J

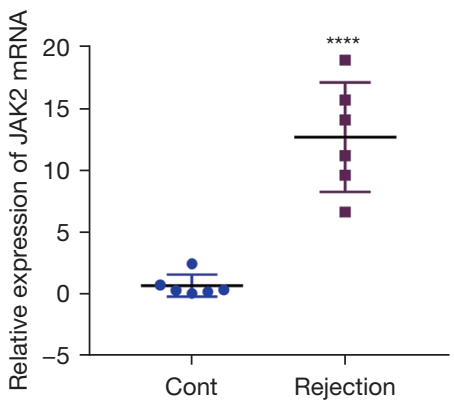

$\mathrm{H}$
B

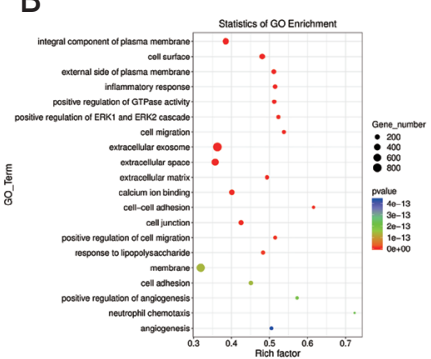

E
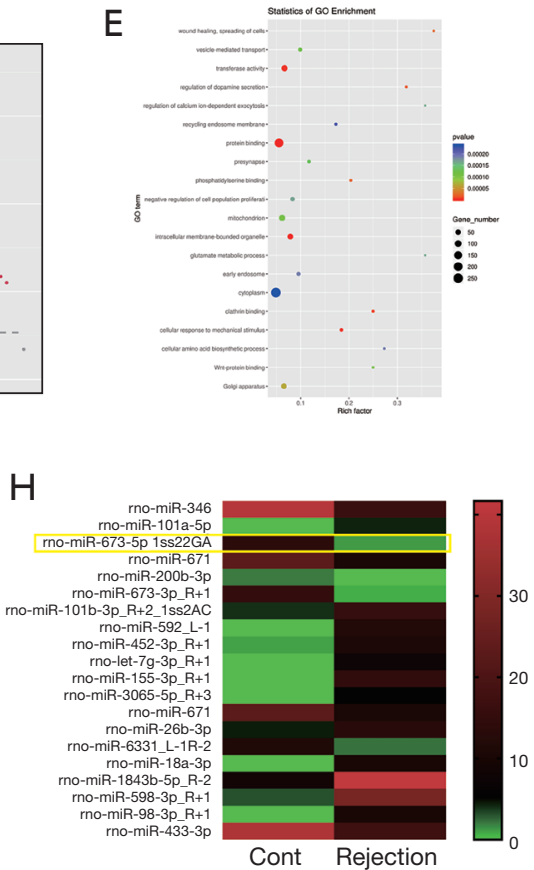

K

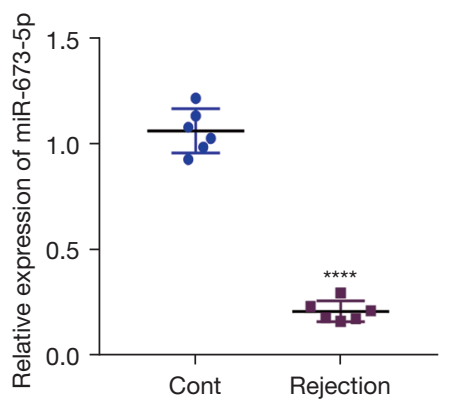

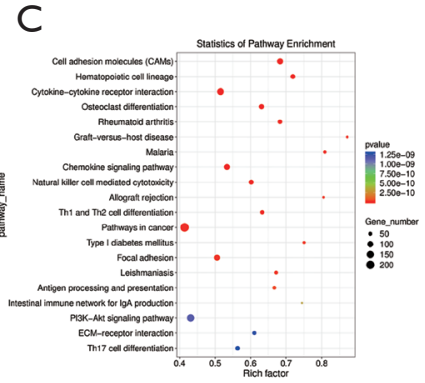

$\mathrm{F}$

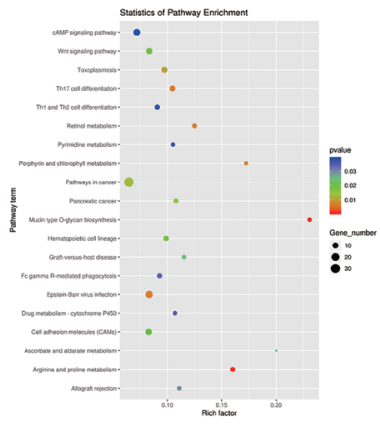

I

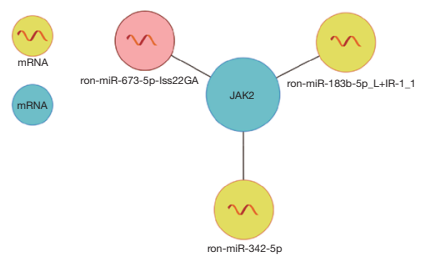

Figure 2 RNA expression profile changes in the cornea after graft rejection. (A) Volcano of differentially expressed mRNAs in the rejection group compared with control group; (B) GO enrichment scatterplot of differentially expressed mRNAs; (C) KEGG pathway enrichment scatterplot of differentially expressed mRNAs; (D) volcano of differentially expressed miRNAs in the rejection group compared with control group; (E) GO enrichment scatterplot of differentially expressed miRNAs; (F) KEGG pathway enrichment scatterplot of differentially expressed miRNAs; $(\mathrm{G}, \mathrm{H})$ heatmaps of differentially expressed mRNAs and miRNAs enriched on the Th17 cell differentiation pathway; (I) miRNAs that were predicted as inhibitors of JAK2 from differentially expressed miRNAs; (J,K) relative expressions of JAK2 mRNA and miR-673-5p in rejected corneal allografts were confirmed by qRT-PCR. ${ }^{* * * *} \mathrm{P}<0.0001$ vs. control group. Cont, control group; Rejection, corneal allograft rejected group. 
and miR-673-5p may regulate Th17 cell differentiation by targeting JAK2.

\section{miR-673-5p targeted inbibits $\mathcal{F A K 2}$ expression and regulates $T$ Th17 cell differentiation}

To study the role miR-673-5p in Th17 cell differentiation, whether miR-673-5p can targetedly bind to JAK2 mRNA and regulate Th17 cell differentiation was determined. As shown in Figure $3 \mathrm{~A}$, there is a miR-673-5p binding site on the position 202-209 of JAK3'UTR2, and the dual luciferase reporter assay revealed that miR-673$5 \mathrm{p}$ could bind to wild type JAK 3'UTR2 (Figure 3B). In cultured rat $\mathrm{CD}^{+} \mathrm{T}$ cells, overexpression of miR-673-5p inhibited the expression of JAK2 and inhibition of miR-673$5 \mathrm{p}$ promoted JAK2 expression (Figure 3C, the effectiveness of the miR-673-5p mimics and inhibitor in transfected $\mathrm{CD}^{+} \mathrm{T}$ cells was measured by RT-qPCR and the result was shown in Figure S1A).

Furthermore, the miR-673-5p inhibitor and mimics were transfected into naïve $\mathrm{CD} 4^{+} \mathrm{T}$ cells, and then the Th17 cell ratio and expression of IL-17, PLGF, and JAK2/ STAT3 signaling was measured. The results showed that miR-673-5p inhibition promoted Th17 cell differentiation and increased the secretion of IL-17 and PLGF, while miR673-5p mimics transfection down-regulated the Th17 cell ratio and secretion of IL-17 and PLGF (Figure 3D,3E). Given that JAK2 is one of the target genes of miR-673$5 \mathrm{p}$ and the JAK2/STAT3 pathway plays important role in Th17 cell differentiation, the expression and activation of JAK2/STAT3 signaling was detected by western blotting. The data revealed that the expression and activation of JAK2/STAT3 signaling was promoted by the miR-673$5 \mathrm{p}$ inhibitor, but was inhibited by miR-673-5p mimics (Figure $3 F-3 H$ ).

\section{miR-673-5p inbibition promotes Th17 cell differentiation by targeting $\mathcal{F} A K 2$}

To further confirm whether miR-673-5p regulates Th17 cell differentiation by targeting JAK2, the inhibitor of JAK2/ STAT3 signaling, AG490, was used to inhibit the activation of JAK2/STAT3. The results showed that inhibition of miR-673-5p promoted the differentiation of Th17 cells (Figure $4 A$ ), the secretion of IL-17 and PLGF (Figure 4B), and the activation of JAK2/STAT3 signaling (Figure $4 C-4 E$ ). Meanwhile, AG490 (an inhibitor of JAK2, the inhibition effect of JAK2 was verified by western blot assay, seen
Figure S1B) treatment reduced Th17 cell differentiation mediated by miR-673-5p inhibitor transfection, decreased the concentrations of IL-17 and PLGF in CM of $\mathrm{CD}^{+} \mathrm{T}$ cells induced by miR-673-5p inhibition, and inhibited the expression and activation of JAK2/STAT3 promoted by the miR-673-5p inhibitor (Figure 4). The above data reveals that inhibition of miR-673-5p expression promotes Th17 cell differentiation by increasing the expression of JAK2 and activation of JAK2/STAT3 signaling.

\section{Th1 7 cell differentiation regulated by miR-673-5p induces angiogenesis by secreting PLGF}

Since CNV is one of the important causes of corneal allograft rejection (20), and PLGF is a kind of "angiolymphokine" closely related to pathological angiogenesis, which links autoimmunity and angiogenesis (33), whether Th17 cell differentiation mediated by miR-673-5p inhibition influences the proliferation, migration, and tube formation ability of HUVECs was detected. After treatment with $\mathrm{CM}$ from each group of $\mathrm{CD}^{+} \mathrm{T}$ cells, the proliferation, migration, and tube formation of HUVECs were promoted by the treatment of untreated $\mathrm{CD}^{+} \mathrm{T}$ cell $\mathrm{CM}$, and were further induced by CM from miR-673$5 \mathrm{p}$-inhibited $\mathrm{CD}^{+} \mathrm{T}$ cells, but were reversed by AG490treated $\mathrm{CD}^{+} \mathrm{T}$ cell $\mathrm{CM}$ (Figure $5 A-5 D$ ). This indicates that miR-673-5p inhibition can promote angiogenesis by inducing Th17 cell differentiation. Furthermore, the PLGF-derived peptide, ZY-1, was used to competitively inhibit PLGF binding to VEGFR. As shown in Figure $5 E-5 H$, the proliferation, migration, and tube formation of HUVECs induced by miR-673-5p-inhibited $\mathrm{CD}^{+} \mathrm{T}$ cell $\mathrm{CM}$ were reversed by $\mathrm{ZY}-1$ treatment, which suggests that PLGF plays important role in CNV induced by miR-673-5p inhibition-mediated Th17 cell differentiation.

\section{Overexpression of miR-673-5p promotes the survival of corneal allografts}

Considering that in vitro experiments have shown that low expression of miR-673-5p promotes angiogenesis by up-regulating JAK2/STAT3-mediated Th17 cell differentiation, whether miR-673-5p overexpression promotes the survival of transplanted allogeneic corneal grafts was detected in our rat model. Mantel-Cox survival curve analysis showed a $100 \%$ rejection of the rejection control group at $20 \mathrm{~d}$ following transplantation, and that 

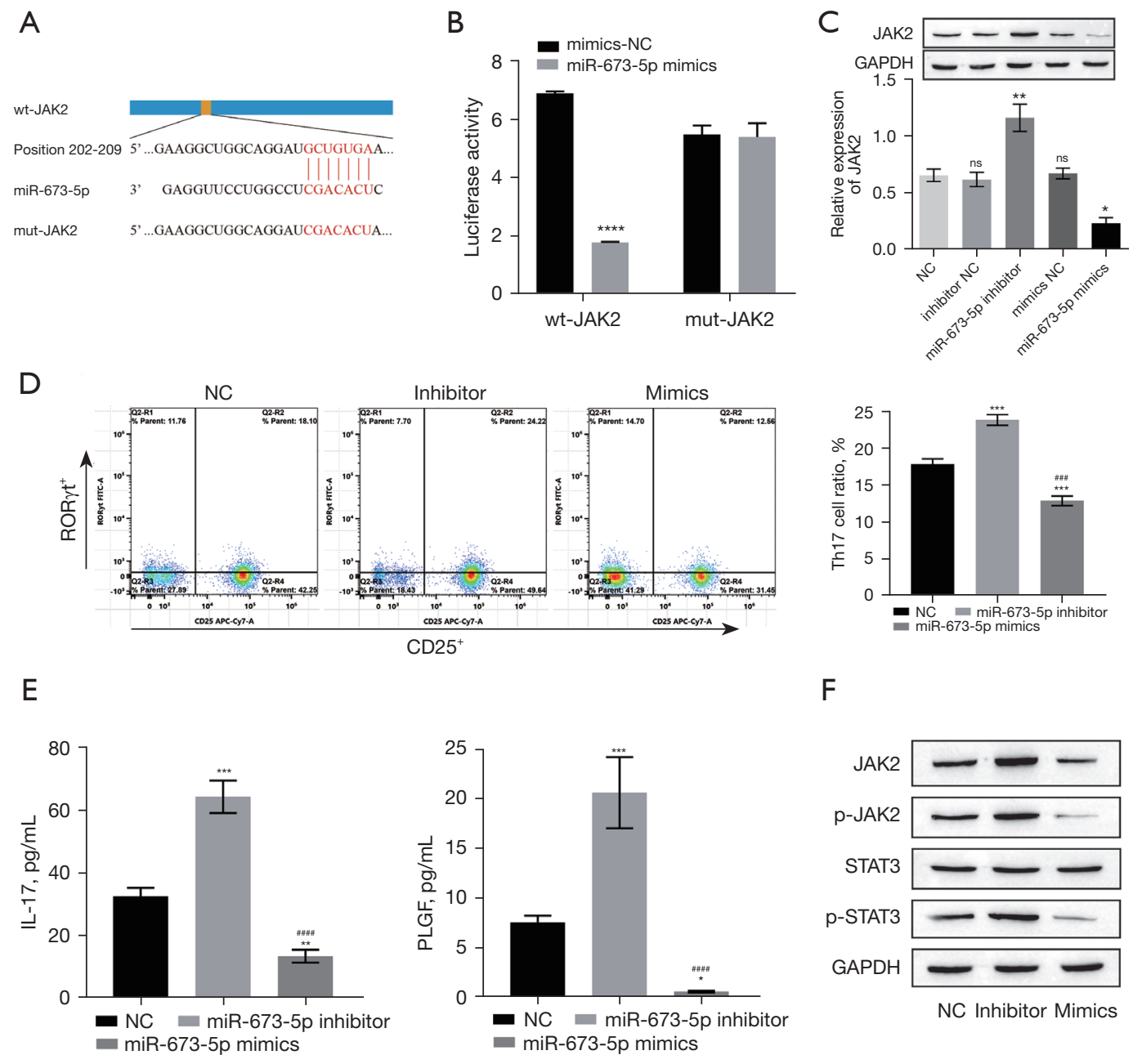

$\mathrm{F}$

G

$\mathrm{H}$
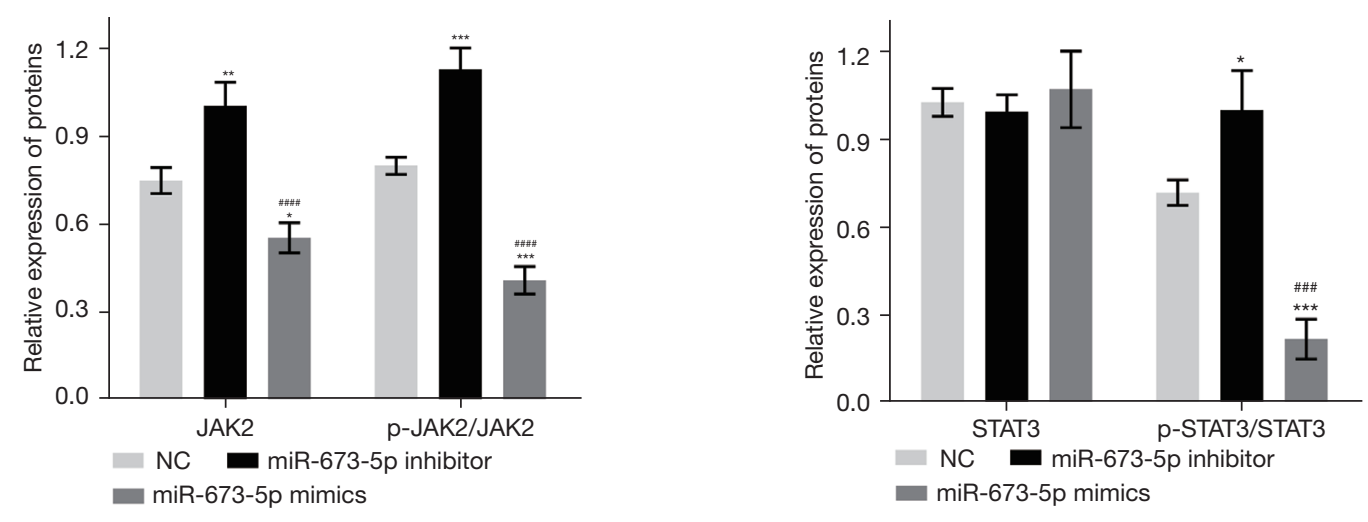

Figure 3 The role of miR-673-5p expression in Th17 cell differentiation. (A) The binding site between miR-673-5p and 3'UTR of JAK2; (B) results of dual luciferase report assay; (C) the expression of JAK2 protein of $\mathrm{CD}^{+} \mathrm{T}$ cells under treatments of miR-673-5p inhibitor and mimics; (D) the influence of miR-673-5p expression on the Th17 cell ratio in cultured CD4 ${ }^{+} \mathrm{T}$ cells; (E) concentrations of IL-17 and PLGF

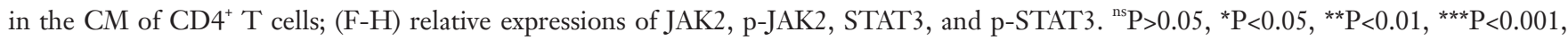
${ }^{* * * *} \mathrm{P}<0.0001$ vs. NC group; ${ }^{\# \# !} \mathrm{P}<0.001,{ }^{\# \# ! \prime} \mathrm{P}<0.0001$ vs. miR-673-5p inhibitor group. NC, negative control; ns, no significance; PLGF, placental growth factor. 


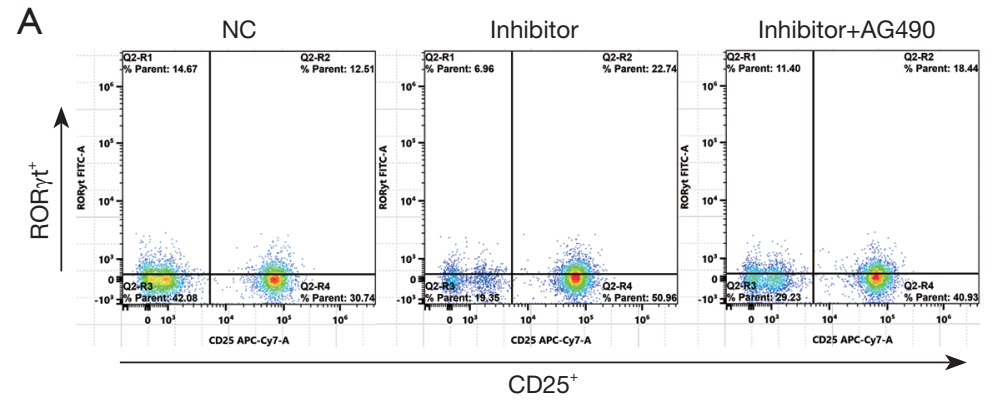

B

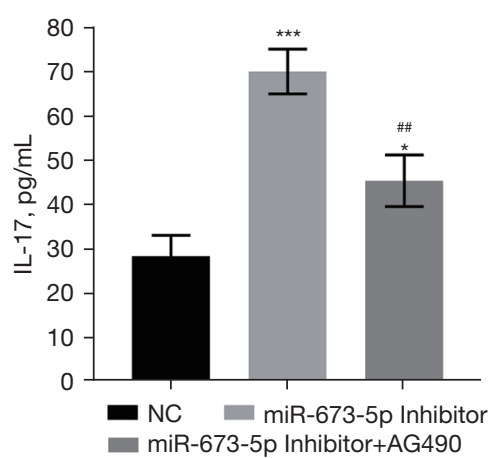

D

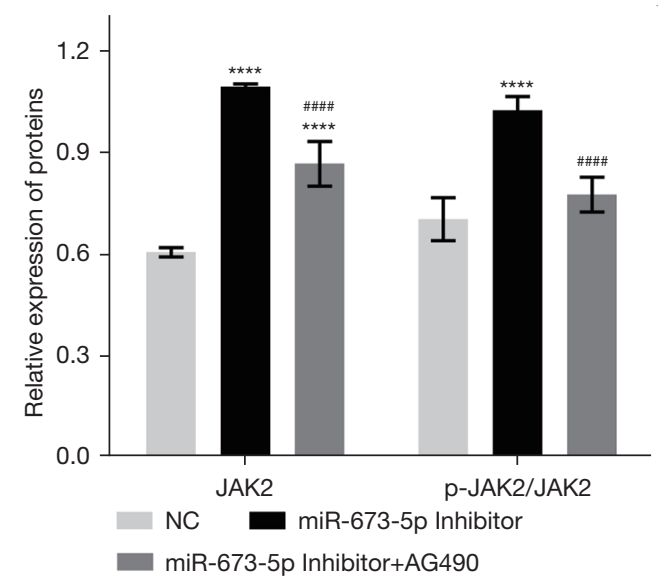

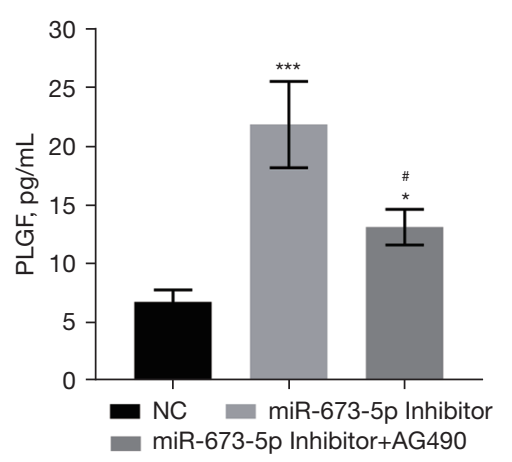

C

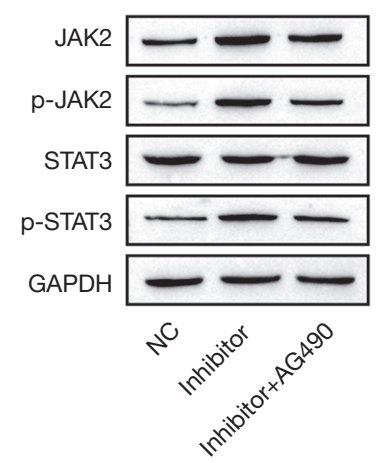

$\mathrm{E}$

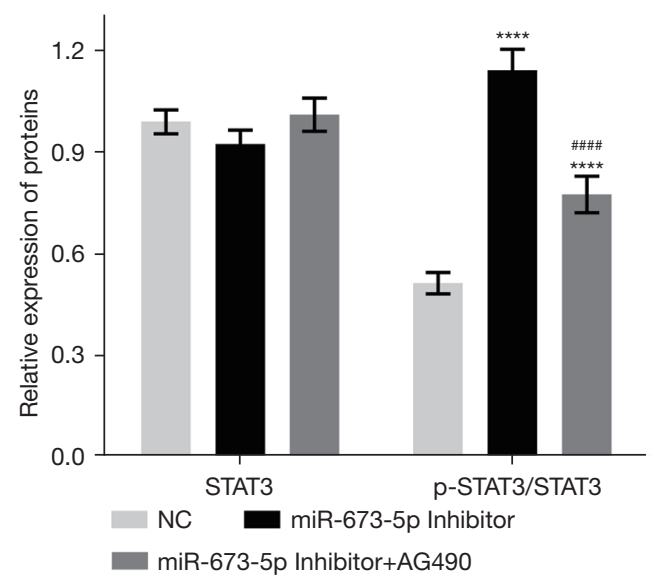

Figure 4 The role of JAK2/STAT3 in miR-673-5p-regulated Th17 cell differentiation. (A) The Th17 cell ratio in cultured CD4 ${ }^{+}$T cells; (B) concentrations of IL-17 and PLGF in the $\mathrm{CM}$ of $\mathrm{CD}^{+} \mathrm{T}$ cells; (C-E) relative expressions of JAK2, p-JAK2, STAT3, and p-STAT3. ${ }^{*} \mathrm{P}<0.05,{ }^{* *} \mathrm{P}<0.01,{ }^{* * *} \mathrm{P}<0.001,{ }^{* * * *} \mathrm{P}<0.0001$ vs. $\mathrm{NC}$ group; ${ }^{\#} \mathrm{P}<0.05,{ }^{\# \#} \mathrm{P}<0.01,{ }^{* \# \# !} \mathrm{P}<0.0001$ vs. miR-673-5p inhibitor group. NC, negative control; PLGF, placental growth factor; CM, culture medium.

treatment with miR-673-5p mimics obviously increased the survival rate of corneal allografts $(\mathrm{P}<0.05$ compared with rejection control group). Meanwhile, JAK2 overexpression reversed the effect of miR-673-5p mimics treatment, although there was no statistically difference (Figure $6 \mathrm{~A}$, there were three JAK2 overexpression vector and the effectiveness of oe-JAK2-1, -2, and -3 was verified by RTqPCR assay in vitro (seen Figure S1C), then oe-JAK2-1 was selected for animal experiment.). In the rejection control group, the allografts exhibited pronounced opacity and 
A

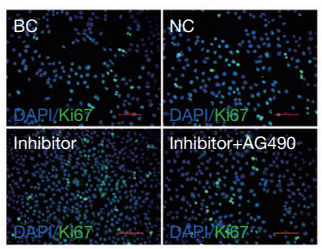

C

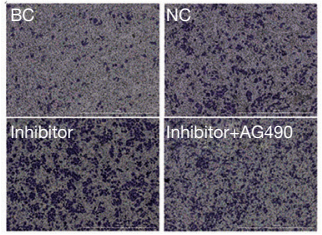

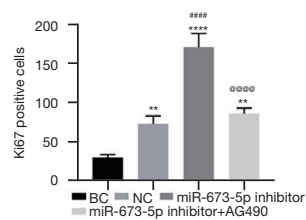

= $B C=N C=$ miR- $-673-50$ inhibito
miR-673-5p inhibitor+AG490
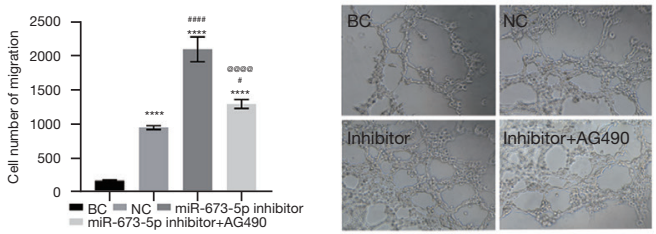
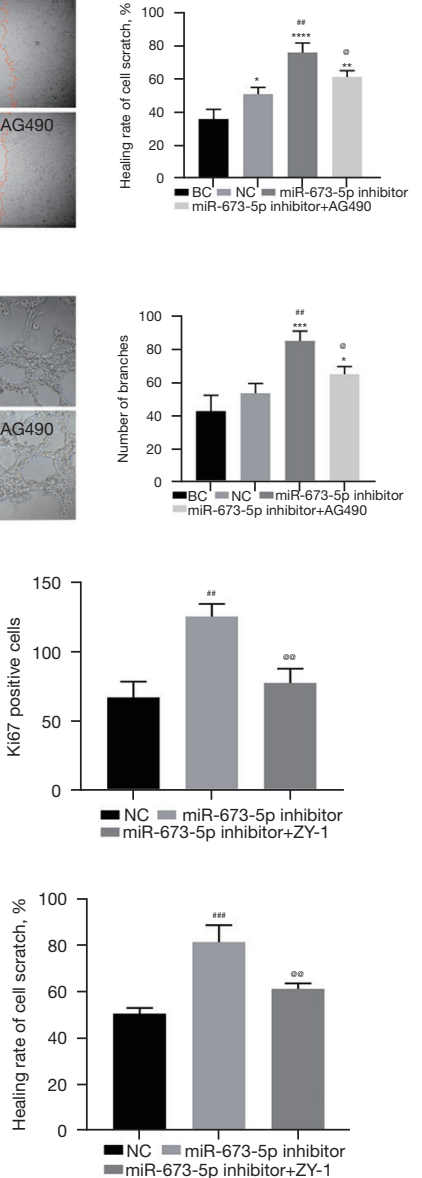

Inhibitor $+Z Y-1$

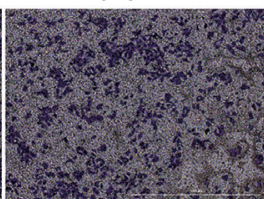

Inhibitor $+Z Y-1$

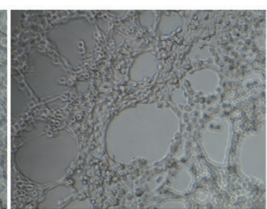

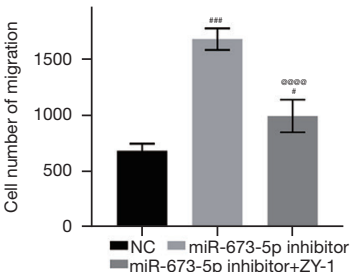

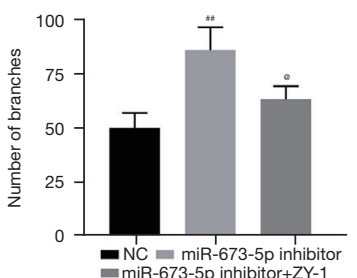

Figure 5 The role of miR-673-5p inhibition-induced Th17 cell differentiation in angiogenesis. (A,E) Ki67 staining of HUVECs treated by $\mathrm{CM}$ of $\mathrm{CD}^{+} \mathrm{T}$ cells, scale bars indicate $100 \mu \mathrm{m}$; (B,F) cell scratch assays of HUVECs treated by $\mathrm{CM}$ of $\mathrm{CD}^{+} \mathrm{T}$ cells (magnification $\times 100$ ); $(\mathrm{C}, \mathrm{G})$ transwell assay of HUVECs treated by $\mathrm{CM}_{\mathrm{C}} \mathrm{CD}^{+} \mathrm{T}$ cells, scale bars indicate $1,000 \mu \mathrm{m} ;(\mathrm{D}, \mathrm{H})$ tube formation ability of HUVECs treated by $\mathrm{CM}$ of $\mathrm{CD}^{+} \mathrm{T}$ cells. BC, HUVECs without $\mathrm{CD}^{+} \mathrm{T}$ cell $\mathrm{CM}$ treatment; $\mathrm{NC}$, HUVECs treated by untreated $\mathrm{CD}^{+}{ }^{+} \mathrm{T}$ cell $\mathrm{CM}$

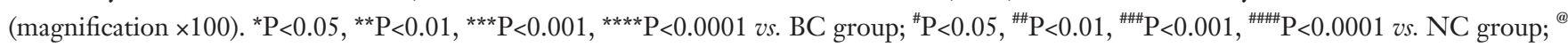
$\mathrm{P}<0.05,{ }^{\circledR}{ }^{\circledR} \mathrm{P}<0.01,{ }^{\circledR}{ }^{\circledR} \mathrm{P}<0.0001$ vs. miR-673-5p inhibitor group. $\mathrm{CM}$, culture medium; BC, blank control; NC, negative control; HUVEC, human umbilical vein endothelial cell; $\mathrm{CM}$, culture medium. 
A

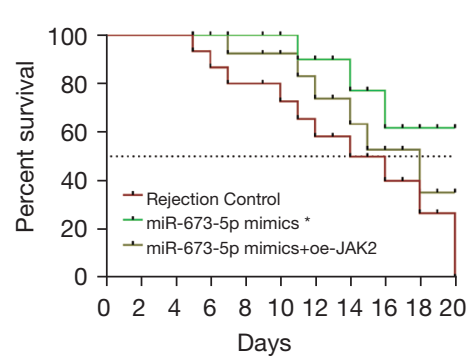

C

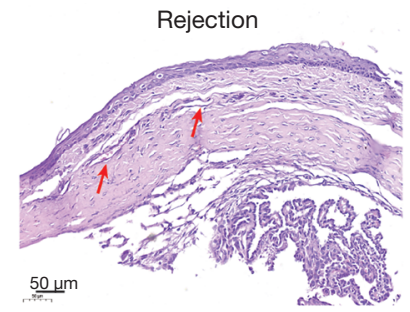

$\mathrm{D}$

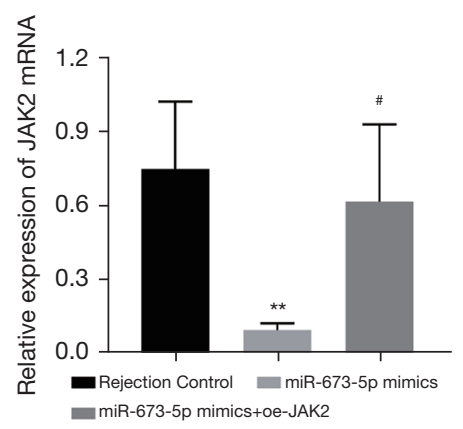

B
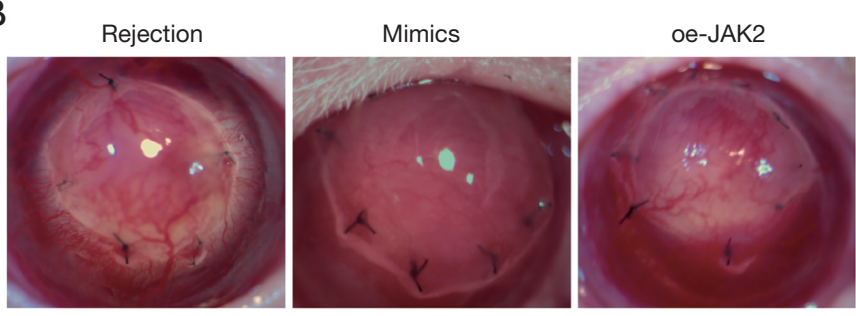

Mimics

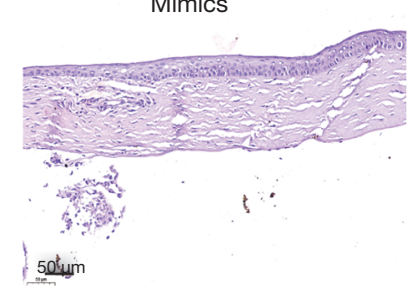

$\mathrm{E}$

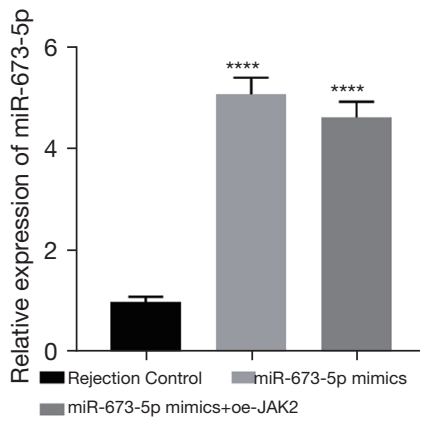

oe-JAK2

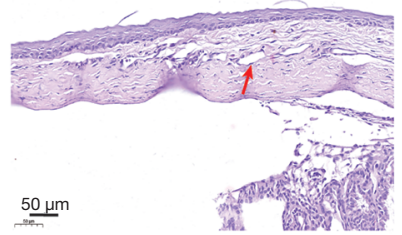

$\mathrm{F}$

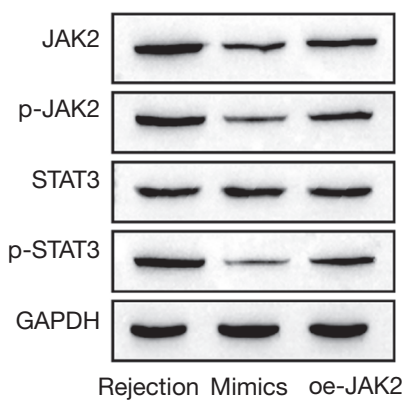

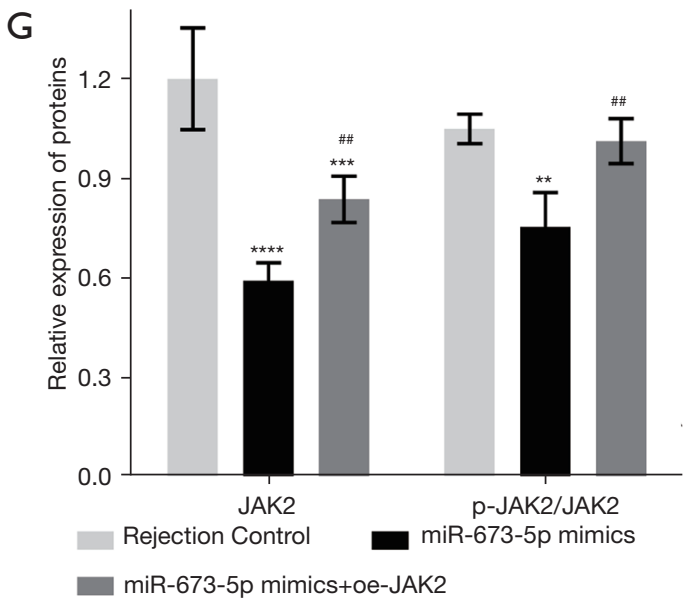

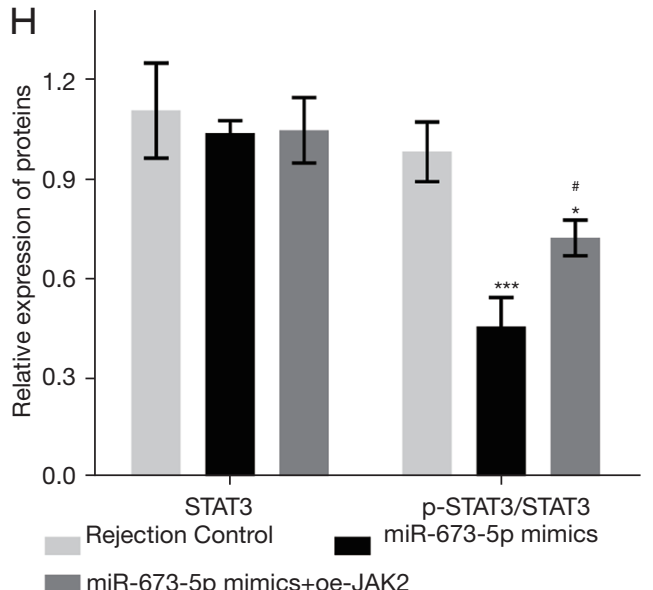

Figure 6 Effect of miR-673-5p overexpression on the survival of corneal allografts. (A) Survival curve of corneal allografts at 3 weeks postoperatively; (B) representative images of corneal allografts $21 \mathrm{~d}$ after transplantation and normal corneas; (C) representative images of H\&E staining on corneal allografts; the red arrows showed the neovascularization in corneal allografts; (D,E) relative expression of JAK2 mRNA and miR-673-5p in corneal allografts; (F-H) relative expressions of JAK2, p-JAK2, STAT3, and p-STAT3 in corneal allografts. ${ }^{*} \mathrm{P}<0.05$, ${ }^{* *} \mathrm{P}<0.01$, ${ }^{* * *} \mathrm{P}<0.001,{ }^{* * *} \mathrm{P}<0.0001$ vs. rejection control group; ${ }^{\#} \mathrm{P}<0.05,{ }^{\# \#} \mathrm{P}<0.01$ vs. miR-673-5p mimics group. Rejection, rejection control; Mimics, miR-673-5p mimics treatment; oe-JAK2, miR-673-5p mimics treatment and JAK2 overexpression; H\&E, hematoxylin and eosin. 
edema, and numerous new vessels grew into the center of the grafts on postoperative day 21 (Figure 6B). Treatment with miR-673-5p mimics reduced the edema of corneal allografts and only small vessels in the graft limbus were observed on postoperative day 21 , while the degree of graft rejection in the JAK2 overexpressed group was higher than the miR-673-5p overexpressed group (Figure 6B). H\&E staining results showed that the overexpression of mir-673$5 \mathrm{p}$ significantly reduced corneal stromal inflammatory cell infiltration, corneal edema, and neovascularization, while JAK2 overexpression partially reversed this protective effect (Figure 6C). Figure 6D,6E showed that the expression of JAK2 mRNA and miR-673-5p in corneal allografts was exactly regulated by miR-673-5p mimics and oe-JAK2 . The expression and activation of JAK2/STAT3 signaling in corneal allografts was significantly inhibited by miR$673-5 \mathrm{p}$ mimics, but was promoted by JAK2 overexpression (Figure 6F-6H).

Furthermore, the ratio of Th17 cells in aqueous humor and peripheral blood at $21 \mathrm{~d}$ postoperatively was determined by flow cytometry. The data showed that compared with rejection control group, the Th17 cell ratio was decreased by miR-673-5p mimics, but was reversed by JAK2 overexpression (Figure $7 A$ ). The concentrations of IL-17 and PLGF in aqueous humor and peripheral blood of different rat groups was consistent with the proportion of Th17 cells in each group (Figure $7 B$ ). In addition, the expression of PLGF and VEGF was examined by immunohistochemical staining and western blotting. As shown in Figure 7C, the expression of PLGF in corneal allografts at $21 \mathrm{~d}$ after transplantation was down-regulated by miR-673-5p mimics treatment, but was promoted by JAK2 overexpression (Figure 7C). Western blotting showed that the expressions of PLGF and VEGF were all inhibited by miR-673-5p mimics after corneal transplantation and were obviously reversed by JAK2 overexpression (Figure $7 D-7 F$ ). These results demonstrate that the overexpression of miR-673-5p can promote the survival of corneal allografts via inhibition of CNV mediated by JAK2/ STAT3-induced Th17 cell differentiation.

\section{Discussion}

Corneal transplantation is the oldest, most common, and most successful form of tissue transplantation. At present, corneal transplantation is the only effective treatment for end-stage blindness. Due to the immune privilege of the anterior chamber of the eye (34), the lack of lymphatic vessels in the corneal transplantation bed (35), the modification of the cell membrane of corneal grafts by molecules such as Fas ligand (FasL) and programmed death ligand 1 (PD-L1) (36), the incidence of corneal transplantation immune rejection is significantly lower than that of heart or kidney transplantation, and its success rate is higher than that of other organ transplantation. However, late rejection is still the main cause of corneal transplantation failure (37). Graft rejection leads to the loss of corneal endothelial cells and opacity of the graft. The failure rate of corneal transplantation may still exceed $50 \%$, even under local and systemic immunosuppressive treatment (2). In the present study, the role of non-coding RNAs (especially miRNAs) in allograft rejection after corneal transplantation was explored and discussed. As the results shown, loss of miR-673-5p expression was determined as a promoter of allograft rejection after corneal transplantation. The data showed JAK2 was the target gene of miR$673-5 \mathrm{p}$, and JAK2 was up-regulated in rejected corneal grafts. The study on molecular mechanisms revealed that low expression of miR-673-5p promoted Th17 cell differentiation by up-regulating the activation of JAK2/ STAT3 signaling, and thus, Th17 cell promoted the progress of CNV by secreting PLGF (Figure 8). These results indicated miR-673-5p overexpression could inhibit Th17 cell differentiation and CNV, and thereby improve the survival of corneal allografts.

Organ transplantation rejection is a complex immunological response involving multiple factors. Although its mechanism remains unclear, studies have confirmed that immune rejection is highly dependent on the directional migration and homing of immune cells to lymphoid tissue or inflammatory sites, including lymphocytes, macrophages, and natural killer (NK) cells, and is regulated by adhesion molecules and chemokines (38). Clinical and experimental data has shown that the destructive attack of immune cells, especially $\mathrm{CD}_{4}{ }^{+} \mathrm{T}$ cells, on the grafts is an important reason for the failure of corneal transplantation due to graft rejection $(32,39,40)$. After activation, $\mathrm{CD}_{4}{ }^{+} \mathrm{T}$ cells can be divided into four subtypes: Th1, Th2, Th17, and regulatory T (Treg) cells. Each subtype of $\mathrm{CD}_{4}{ }^{+} \mathrm{T}$ cell produces its own specific cytokines and participates in graft inflammation and rejection (41). Th17 cells express the transcription factor, ROR $\gamma$ t, and induce leukocyte infiltration, promote chemokine expression, and mediate inflammation in the immune response after transplantation by secreting various 
A
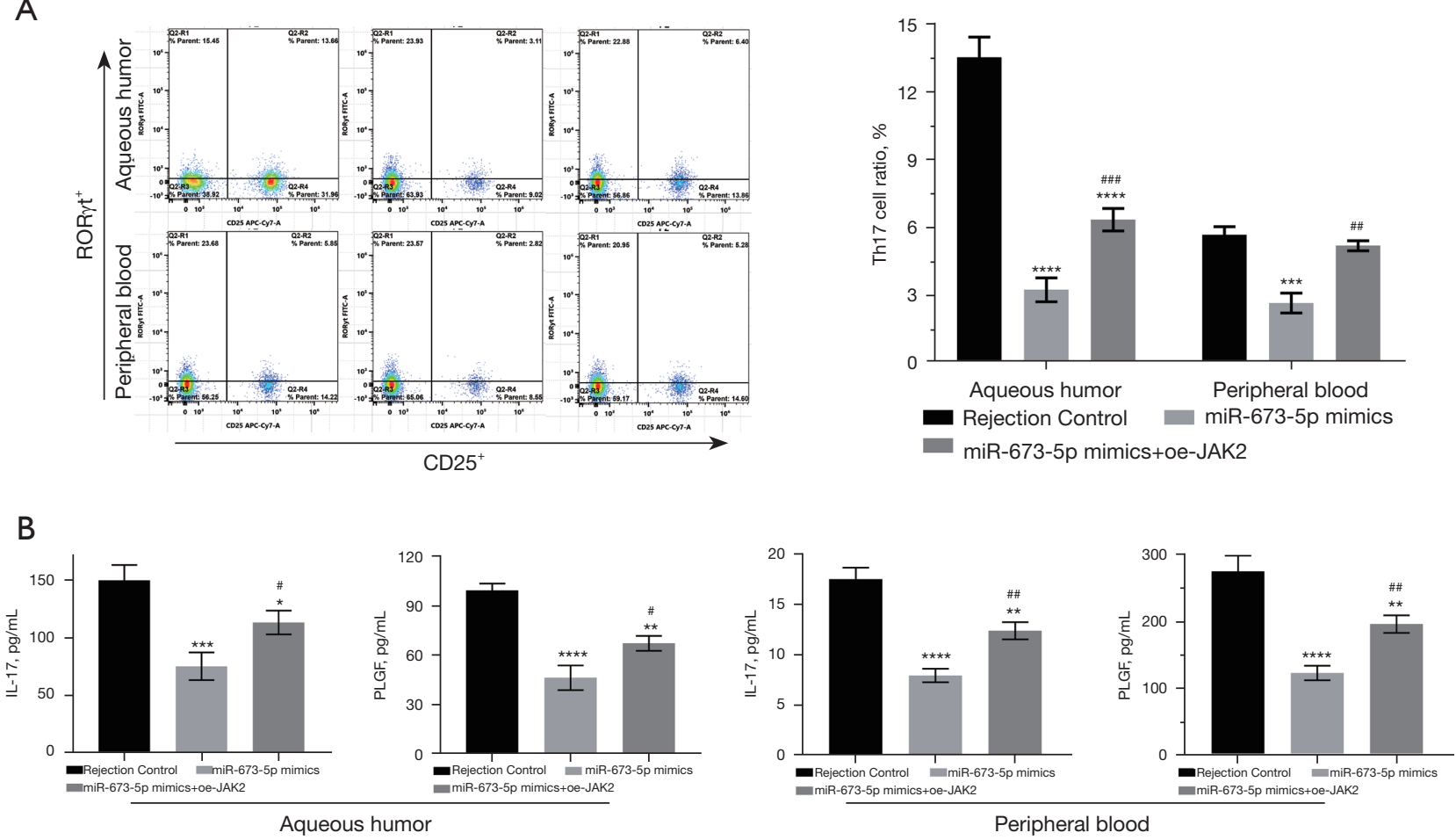

C
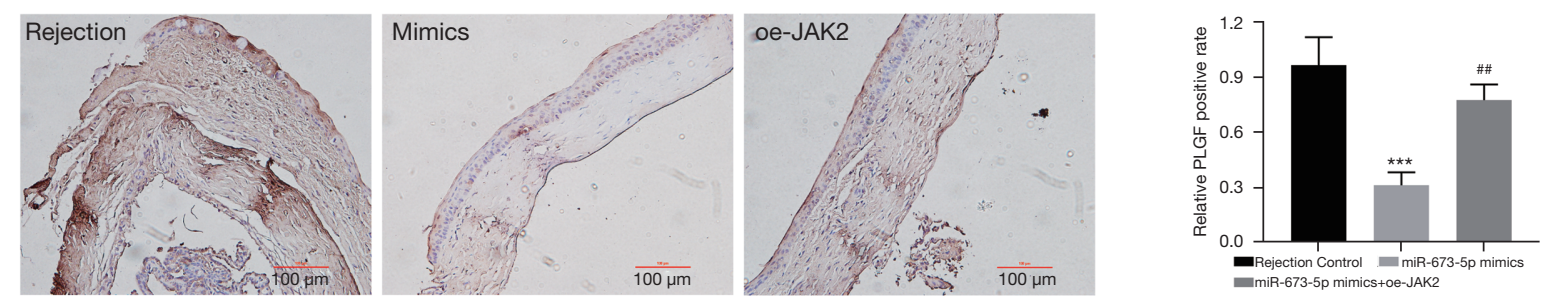

D

$\mathrm{E}$

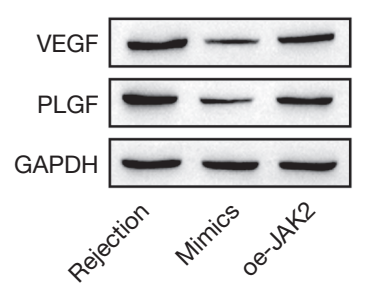

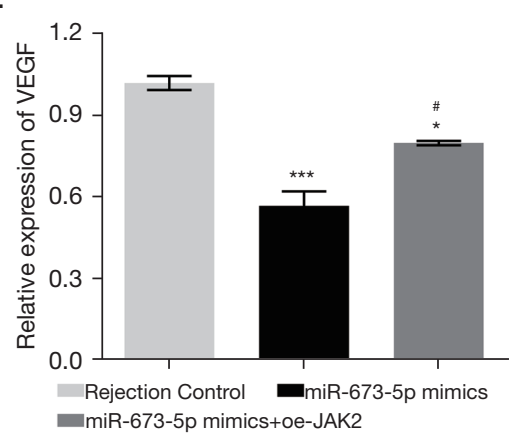

$\mathrm{F}$

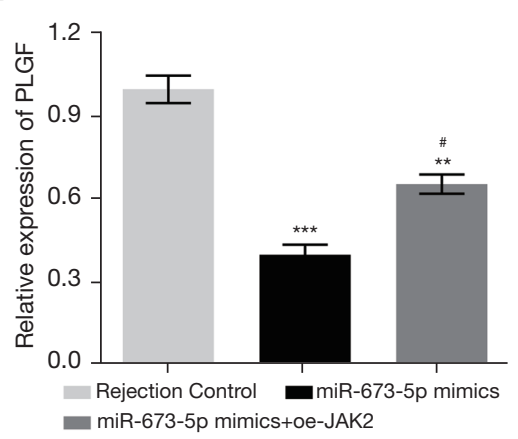

Figure 7 Effect of miR-673-5p overexpression on Th17 cell differentiation and angiogenesis of corneal allografts. (A) Ratio of Th17 cells in aqueous humor and peripheral blood of rats at $21 \mathrm{~d}$ after corneal transplantation; (B) concentrations of IL-17 and PLGF in aqueous humor and peripheral blood; (C) immunohistochemical staining of corneal allografts by anti-PLGF antibody; (D) relative expression of VEGF and PLGF in corneal allografts; (E,F) the visual data maps of relative expression of VEGF and PLGF. ${ }^{*} \mathrm{P}<0.05,{ }^{* *} \mathrm{P}<0.01,{ }^{* * *} \mathrm{P}<0.001$, ${ }^{* * * *} \mathrm{P}<0.0001$ vs. rejection control group; ${ }^{*} \mathrm{P}<0.05,{ }^{\# \#} \mathrm{P}<0.01,{ }^{\# \#+} \mathrm{P}<0.001$ vs. miR-673-5p mimics group. Rejection, rejection control; Mimics, miR-673-5p mimics treatment; oe-JAK2, miR-673-5p mimics treatment and JAK2 overexpression; PLGF, placental growth factor; VEGF, vascular endothelial growth factor. 


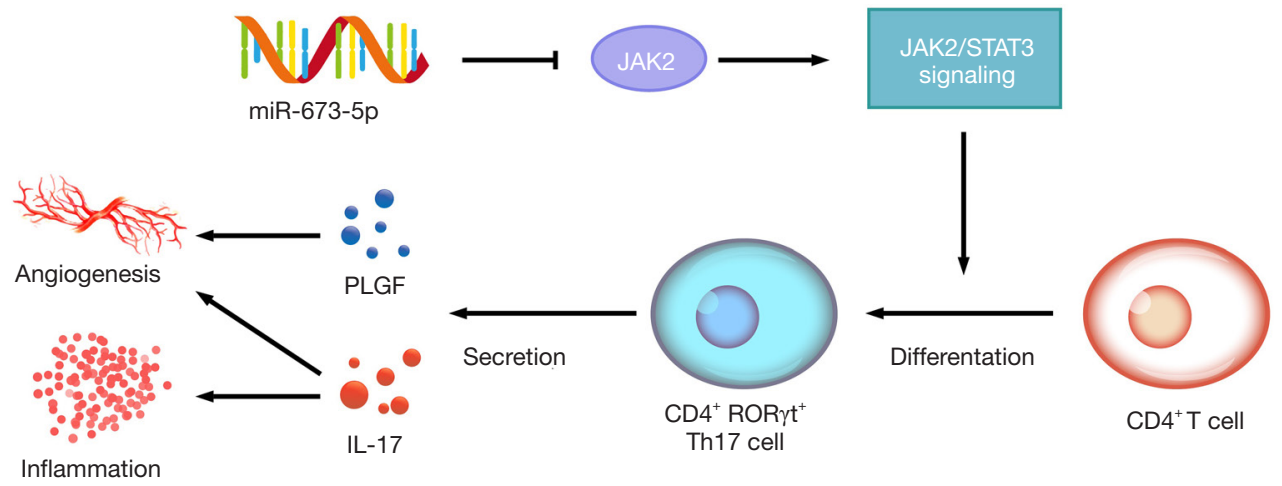

Figure 8 Graphical abstract. miR-673-5p acts as a significant regulator in corneal allograft rejection. miR-673-5p can inhibit Th17 cell differentiation by targeting to JAK2. Low expression of miR-673-5p promotes the differentiation of Th17 cells by increasing the expression and activation of JAK2/STAT3 signaling, thereby inducing CNV mediated by Th17 cell-secreted PLGF. CNV, corneal neovascularization; PLGF, placental growth factor.

proinflammatory cytokines such as IL-17, IL-21, and IL$22(42,43)$. Treg cells are anti-inflammatory helper $\mathrm{T}$ cells; the balance of Treg/Th17 plays a significant role in corneal allograft rejection $(7,10,13)$. This study confirmed that Th17 cell differentiation was up-regulated in aqueous humor and peripheral blood at $21 \mathrm{~d}$ postoperatively, which was induced by miR-673-5p inhibition.

$\mathrm{CNV}$ is one of the important causes of allograft rejection after corneal transplantation $(19,20)$. Studies have shown that Th17 cells are involved in the regulation of CNV development, and its characteristic cytokine, IL17 , is related to the pathogenesis of $\mathrm{CNV}$, in addition to promoting an inflammatory response $(44,45)$. However, the molecular mechanisms involved in Th17 cellmediated CNV remains unclear. Angiogenesis is mainly related to the expression of angiogenic factors, especially VEGF. As a member of the VEGF family, PLGF was reported to be primarily involved in inflammation and pathological angiogenesis (23). Previous studies have shown that PLGF is also involved in the development of CNV (24,25). Interestingly, PLGF can be selectively secreted by Th17 cells, which build a crosstalk between vascular endothelial cells and helper T cells (26). The results of this study revealed that the concentration of PLGF in aqueous humor and peripheral blood of rats was obviously increased at $21 \mathrm{~d}$ after surgery. Furthermore, we found that miR-673-5p inhibition-induced Th17 cell differentiation could promote the proliferation, migration, and tube formation of HUVECs by secreting PLGF, which suggested that Th17 cells-induced CNV during corneal allograft rejection was closely related to the expression of PLGF.

In summary, the present study revealed that the expression of miR-673-5p acts as a significant regulator in corneal allograft rejection (Figure 8). Low expression of miR-673-5p promotes the differentiation of Th17 cells by increasing the expression and activation of JAK2/STAT3 signaling, thus inducing CNV mediated by Th17 cellsecreted PLGF. This study indicates that the overexpression of miR-673-5p may be an effective therapy to improve the survival rate of corneal allografts following transplantation. However, this study did not discuss the causes of corneal allografts rejection (such as the different time of donor heart death, vascular and lymphatic hyperplasia of graft bed, and post-transplant infection, etc.), and did not verify the expression of JAK2, miR-673-5p and Th17 cells in peripheral blood and aqueous humor of patients with corneal allografts rejection. Therefore, there are still great limitations in this study, we will further improve the research program and make in-depth exploration in the follow-up study.

\section{Acknowledgments}

Funding: This work was supported by the Associated Project of Yunnan Province Science \& Technology Department and Kunming Medical University Basic Research for Application [2018FE001-(010)].

\section{Footnote}

Reporting Checklist: The authors have completed the 
ARRIVE reporting checklist. Available at https://dx.doi. org/10.21037/atm-21-2051

Data Sharing Statement: Available at https://dx.doi. org/10.21037/atm-21-2051

Conflicts of Interest: All authors have completed the ICMJE uniform disclosure form (available at https://dx.doi. org/10.21037/atm-21-2051). The authors have no conflicts of interest to declare.

Ethical Statement: The authors are accountable for all aspects of the work in ensuring that questions related to the accuracy or integrity of any part of the work are appropriately investigated and resolved. All animal experimental protocols were approved by the Animal Experimental Ethical Inspection of the Affiliated Calmette Hospital of Kunming Medical University (Approval No. YLS2020-18), and the animals were handled according to the management requirements of the Animal Management Association of the Affiliated Calmette Hospital of Kunming Medical University.

Open Access Statement: This is an Open Access article distributed in accordance with the Creative Commons Attribution-NonCommercial-NoDerivs 4.0 International License (CC BY-NC-ND 4.0), which permits the noncommercial replication and distribution of the article with the strict proviso that no changes or edits are made and the original work is properly cited (including links to both the formal publication through the relevant DOI and the license). See: https://creativecommons.org/licenses/by-ncnd $/ 4.0 /$.

\section{References}

1. Dunker SL, Armitage WJ, Armitage M, et al. Practice patterns of corneal transplantation in Europe: first report by the European Cornea and Cell Transplantation Registry. J Cataract Refract Surg. 2021;47:865-9.

2. Amouzegar A, Chauhan SK, Dana R. Alloimmunity and Tolerance in Corneal Transplantation. J Immunol 2016;196:3983-91.

3. Cunnusamy K, Chen PW, Niederkorn JY. IL-17 promotes immune privilege of corneal allografts. J Immunol 2010;185:4651-8.

4. Hegde S, Beauregard C, Mayhew E, et al. CD4(+) T-cell-mediated mechanisms of corneal allograft rejection: role of Fas-induced apoptosis. Transplantation 2005;79:23-31.

5. Hattori T, Usui Y, Okunuki Y, et al. Blockade of the OX40 ligand prolongs corneal allograft survival. Eur J Immunol 2007;37:3597-604.

6. Yin XT, Zobell S, Jarosz JG, et al. Anti-IL-17 therapy restricts and reverses late-term corneal allorejection. J Immunol 2015;194:4029-38.

7. Li S, Yu J, Guo C, et al. The Balance of Th1/Th2 and LAP+Tregs/Th17 Cells Is Crucial for Graft Survival in Allogeneic Corneal Transplantation. J Ophthalmol 2018;2018:5404989.

8. Chen H, Wang W, Xie H, et al. A pathogenic role of IL17 at the early stage of corneal allograft rejection. Transpl Immunol 2009;21:155-61.

9. Park JS, Lee J, Lim MA, et al. JAK2-STAT3 blockade by AG490 suppresses autoimmune arthritis in mice via reciprocal regulation of regulatory $\mathrm{T}$ Cells and Th17 cells. J Immunol 2014;192:4417-24.

10. Zheng Y, Wang Z, Deng L, et al. Modulation of STAT3 and STAT5 activity rectifies the imbalance of Th17 and Treg cells in patients with acute coronary syndrome. Clin Immunol 2015;157:65-77.

11. Gu FM, Li QL, Gao Q, et al. IL-17 induces AKTdependent IL-6/JAK2/STAT3 activation and tumor progression in hepatocellular carcinoma. Mol Cancer 2011;10:150.

12. Wei C, Ma L, Chi H, et al. The NLRP3 inflammasome regulates corneal allograft rejection through enhanced phosphorylation of STAT3. Am J Transplant 2020;20:3354-66.

13. You G, Cao H, Yan L, et al. MicroRNA-10a-3p mediates Th17/Treg cell balance and improves renal injury by inhibiting REG3A in lupus nephritis. Int Immunopharmacol 2020;88:106891.

14. Angelou CC, Wells AC, Vijayaraghavan J, et al. Differentiation of Pathogenic Th17 Cells Is Negatively Regulated by Let-7 MicroRNAs in a Mouse Model of Multiple Sclerosis. Front Immunol 2020;10:3125.

15. Honardoost MA, Naghavian R, Ahmadinejad F, et al. Integrative computational mRNA-miRNA interaction analyses of the autoimmune-deregulated miRNAs and well-known Th17 differentiation regulators: An attempt to discover new potential miRNAs involved in Th17 differentiation. Gene 2015;572:153-62.

16. Roy S, Awasthi A. Emerging roles of noncoding RNAs in $\mathrm{T}$ cell differentiation and functions in autoimmune diseases. Int Rev Immunol 2019;38:232-45. 
17. Wang T, Li F, Geng W, et al. MicroRNA-122 ameliorates corneal allograft rejection through the downregulation of its target CPEB1. Cell Death Discov 2017;3:17021.

18. Lu X, Wu J, Ma M, et al. An integrated deep sequencing analysis of microRNAs in transplanted corneas. Mol Immunol 2018;101:429-39.

19. Di Zazzo A, Kheirkhah A, Abud TB, et al. Management of high-risk corneal transplantation. Surv Ophthalmol 2017;62:816-27.

20. Zhong W, Montana M, Santosa SM, et al. Angiogenesis and lymphangiogenesis in corneal transplantation-A review. Surv Ophthalmol 2018;63:453-79.

21. Faraj LA, Elalfy MS, Said DG, et al. Fine needle diathermy occlusion of corneal vessels. Br J Ophthalmol 2014;98:1287-90.

22. Inomata T, Mashaghi A, Di Zazzo A, et al. Kinetics of Angiogenic Responses in Corneal Transplantation. Cornea 2017;36:491-6.

23. Van Bergen T, Etienne I, Cunningham F, et al. The role of placental growth factor (PlGF) and its receptor system in retinal vascular diseases. Prog Retin Eye Res 2019;69:116-36.

24. Lu Y, Zheng Y, Ai J, et al. Therapeutic effects of a novel PIGF-1 derived peptide, ZY-1, on corneal neovascularization in vitro and in vivo. Discov Med 2016;21:349-61.

25. Zheng $\mathrm{Y}, \mathrm{Gu} \mathrm{Q}, \mathrm{Xu} \mathrm{X}$. Inhibition of ocular neovascularization by a novel peptide derived from human placenta growth factor-1. Acta Ophthalmol 2012;90:e512-23.

26. Yoo SA, Kim M, Kang MC, et al. Placental growth factor regulates the generation of TH17 cells to link angiogenesis with autoimmunity. Nat Immunol 2019;20:1348-59.

27. Liu Z, Lin H, Huang C, et al. Development and Effects of FTY720 Ophthalmic Solution on Corneal Allograft Survival. Sci Rep 2015;5:16468.

28. Larkin DF, Calder VL, Lightman SL. Identification and characterization of cells infiltrating the graft and aqueous humour in rat corneal allograft rejection. Clin Exp Immunol 1997;107:381-91.

29. Fazal N, Raziuddin S, Khan M, et al. Antigen presenting cells (APCs) from thermally injured and/or septic rats modulate CD4+ T cell responses of naive rat. Biochim Biophys Acta 2006;1762:46-53.

30. Zhou YF, Shi LJ, Yao J, et al. Microarray Analysis of circRNA Expression Pattern in Corneal
Neovascularization. Cornea 2019;38:1443-9.

31. Wu P, Zhang D, Geng Y, et al. Circular RNA-ZNF609 regulates corneal neovascularization by acting as a sponge of miR-184. Exp Eye Res 2020;192:107937.

32. Pastak M, Kleff V, Saban DR, et al. Gene Therapy for Modulation of T-Cell-Mediated Immune Response Provoked by Corneal Transplantation. Hum Gene Ther 2018;29:467-79.

33. Yoo SA, Kim M, Kang MC, et al. Placental growth factor regulates the generation of TH17 cells to link angiogenesis with autoimmunity. Nat Immunol 2019;20:1348-59.

34. Jonas JB, Rank RM, Budde WM. Immunologic graft reactions after allogenic penetrating keratoplasty. Am J Ophthalmol 2002;133:437-43.

35. Cursiefen C, Chen L, Dana MR, et al. Corneal lymphangiogenesis: evidence, mechanisms, and implications for corneal transplant immunology. Cornea 2003;22:273-81.

36. Amouzegar A, Chauhan SK, Dana R. Alloimmunity and Tolerance in Corneal Transplantation. J Immunol 2016;196:3983-91.

37. Khodadoust AA, Silverstein AM. Transplantation and rejection of individual cell layers of the cornea. Invest Ophthalmol 1969;8:180-95.

38. Wang G, Kong G, Li XC. Adaptive features of innate immune cells and their relevance to graft rejection. Curr Opin Organ Transplant 2019;24:664-9.

39. Mahabadi N, Czyz CN, Tariq M, et al. Corneal Graft Rejection. StatPearls Treasure Island (FL), 2020.

40. Koudouna E, Okumura N, Okazaki Y, et al. Immune Cells on the Corneal Endothelium of an Allogeneic Corneal Transplantation Rabbit Model. Invest Ophthalmol Vis Sci 2017;58:242-51.

41. Lin CM, Gill RG. Direct and indirect allograft recognition: pathways dictating graft rejection mechanisms. Curr Opin Organ Transplant 2016;21:40-4.

42. Yin XT, Zobell S, Jarosz JG, et al. Anti-IL-17 therapy restricts and reverses late-term corneal allorejection. J Immunol 2015;194:4029-38.

43. Wang X, Wang W, Xu J, et al. All-trans retinoid acid promotes allogeneic corneal graft survival in mice by regulating Treg-Th17 balance in the presence of TGF- $\beta$. BMC Immunol 2015;16:17.

44. Xia L, Zhang S, Cao Z, et al. Interleukin-17 enhanced immunoinflammatory lesions in a mouse model 
Page 18 of 18

of recurrent herpetic keratitis. Microbes Infect 2013;15:126-39.

45. Abdelfattah NS, Amgad M, Zayed AA. Host immune cellular reactions in corneal neovascularization. Int J

Cite this article as: Cao Q, Li Y, Li Y, Li L. Loss of miR$673-5 \mathrm{p}$ expression in the cornea promotes rat corneal allograft rejection by promoting Th17 cell differentiation mediated by JAK2/STAT3. Ann Transl Med 2021;9(18):1409. doi: 10.21037/ atm-21-2051

\section{Cao et al. Role of miR-673-5p in corneal allograft rejection}

Ophthalmol 2016;9:625-33.

(English Language Editor: A. Kassem) 


\section{Supplementary}

A

C
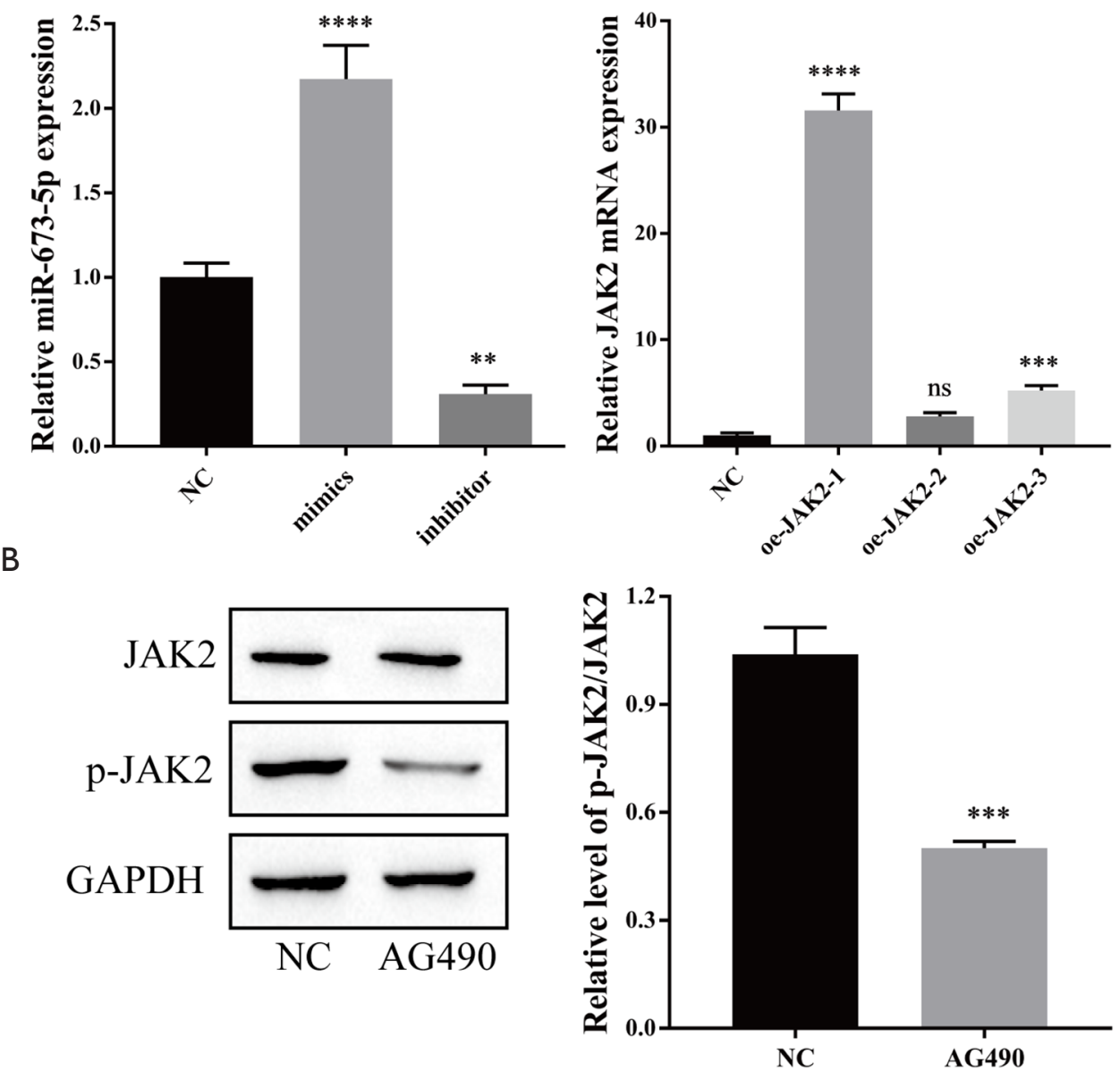

Figure S1 The effectiveness of the miR-673-5p mimics and inhibitor, and AG490 and oe-JAK2. (A) the effect of miR-673-5p mimics and inhibitor on miR-673-5p expression in $\mathrm{CD} 4{ }^{+} \mathrm{T}$ cells; (B) the effect of AG490 on JAK2 phosphorylation in $\mathrm{CD} 4{ }^{+} \mathrm{T}$ cells. ${ }^{\text {ns }} \mathrm{P}>0.05,{ }^{* *} \mathrm{P}<0.01$, ${ }^{* * *} \mathrm{P}<0.001,{ }^{* * * *} \mathrm{P}<0.0001$ vs. NC group. NC, negative control; AG490, the inhibitor of JAK2/STAT3 signaling; (C) the effect of different JAK2 overexpression vectors (oe-JAK2-1, -2, -3) on JAK2 mRNA expression in CD4+ T cells. 